\title{
Strain Gage Loads Calibration Testing With Airbag Support for the Gulfstream III SubsoniC Research Aircraft Testbed (SCRAT)
}

\author{
William A. Lokos ${ }^{1}$, Eric J. Miller², Larry D. Hudson ${ }^{3}$, Andrew C. Holguin ${ }^{4}$, David C. Neufeld ${ }^{5}$, Ronnie Haraguchi ${ }^{6}$ \\ NASA Armstrong Flight Research Center, Edwards, CA, 93523
}

\begin{abstract}
This paper describes the design and conduct of the strain-gage load calibration ground test of the SubsoniC Research Aircraft Testbed, Gulfstream III aircraft, and the subsequent data analysis and results. The goal of this effort was to create and validate multi-gage load equations for shear force, bending moment, and torque for two wing measurement stations. For some of the testing the aircraft was supported by three airbags in order to isolate the wing structure from extraneous load inputs through the main landing gear. Thirty-two strain gage bridges were installed on the left wing. Hydraulic loads were applied to the wing lower surface through a total of 16 load zones. Some dead-weight load cases were applied to the upper wing surface using shot bags. Maximum applied loads reached 54,000 lb. Twenty-six load cases were applied with the aircraft resting on its landing gear, and 16 load cases were performed with the aircraft supported by the nose gear and three airbags around the center of gravity. Maximum wing tip deflection reached 17 inches. An assortment of 2, 3, 4, and 5 strain-gage load equations were derived and evaluated against independent check cases. The better load equations had root mean square errors less than 1 percent. Test techniques and lessons learned are discussed.
\end{abstract}

\section{Nomenclature}

$\begin{array}{ll}\text { ACTE } & =\text { Adaptive Compliant Trailing Edge } \\ \text { AFRC } & =\text { Armstrong Flight Research Center } \\ \text { ANSI } & =\text { American National Standards Institute } \\ \text { DAS } & =\text { data acquisition system } \\ \text { CG } & =\text { center of gravity } \\ \text { EQDE } & =\text { EQuation DErivation } \\ \text { FEM } & =\text { finite element model } \\ \text { FLL } & =\text { Flight Loads Laboratory } \\ \text { GII } & =\text { Gulfstream II } \\ \text { GIII } & =\text { Gulfstream III } \\ \text { HPU } & =\text { hydraulic power unit } \\ \text { IADS } & =\text { Interactive Analysis and Display System } \\ \text { LRT } & =\text { linear resistance transducer } \\ \text { MLCS } & =\text { mechanical load control system } \\ \text { NASA } & =\text { National Aeronautics and Space Administration } \\ \text { POL } & =\text { percent of limit } \\ \text { RBS } & =\text { Rear Beam Station } \\ \text { RMS } & =\text { root mean square } \\ \text { RTFE } & =\text { Real Time Front End }\end{array}$

${ }^{1}$ Research Engineer, Aerostructures Branch, P.O. Box 273/MS 48202A, AIAA Member.

2 Research Engineer, Aerostructures Branch, P.O. Box 273/MS 48202A, AIAA Member.

${ }^{3}$ Chief Test Engineer, Aerostructures Branch, P.O. Box 273/MS 48201C, AIAA Nonmember.

${ }^{4}$ Test Engineer, Aerostructures Branch, P.O. Box 273/MS 48201C, AIAA Nonmember.

${ }^{5}$ Engineering Technician, Aerostructures Branch, P.O. Box 273/MS 48201D, AIAA Nonmember.

${ }^{6}$ Test Operations Manager, Aerostructures Branch, P.O. Box 273/MS 48201D, AIAA Nonmember. 


\section{Introduction}

$\mathrm{T}$ The SubsoniC Research Aircraft Testbed (SCRAT) Gulfstream III (GIII) aircraft (Gulfstream Aerospace Corporation, Savannah, Georgia), ${ }^{1}$ shown in Fig. 1, has been prepared to flight-test the Adaptive Compliant Trailing Edge (ACTE) smoothly curving flaps, shown in Fig. 2. During the flight-test program the ACTE flaps will replace the conventional Fowler type flaps. It is planned to test these experimental flaps at test points outside the cleared Fowler flap envelope. External load predictions were performed which indicate the potential for overloading the wing structure due to the planned higher dynamic pressure flight conditions. This load prediction effort indicated two wing stations were at most risk for exceeding limits. For safety-of-flight and real-time test point clearance these two wing stations were selected for load measurement. Sixteen four-active-arm strain-gage bridges were installed at each of these measurement stations on the left wing as shown in Fig. 3 to provide for the required load measurements. Engineering judgment, prior loads analysis, and loads calibration work ${ }^{2,3}$ contributed to the sensor plan. To develop the multi-gage shear force, bending moment and torque load equations, a Load Calibration Test was performed in the National Aeronautics and Space Administration (NASA) Armstrong Flight Research Center (AFRC) Flight Loads Laboratory (FLL) ${ }^{4}$. This test was performed with the aircraft resting on all three landing gear. Load equations were derived from the recorded test data, however, other test data indicated the potential that as the main gear loads varied the wing, strain-gage signals would change. In one of these other tests, referred to as the Live Load Test, the wing strain-gage signals were observed and recorded while 20 people boarded the aircraft. In another test, referred to as the Fueling Test, the strain-gage signals were acquired while the aircraft was fueled. In both tests the wing strain-gage outputs changed noticeably. The main gear are attached to the rear spar just inboard of the inboard load measurement station, and it became clear that variable gear reaction load meant some amount of additional variation in strain-gage output. This load variability cast some doubt on the accuracy of the load equations produced from the Load Calibration Test. There was already a plan to repeat some of the Load Calibration Test points to validate the on-board data system once it was reinstalled. This test was called the Check Load Test. It was concluded from the consideration of the Live Load Test and the Fueling Test that it would be valuable to also repeat some load cases with the aircraft somehow supported off the main gear. An airbag support scheme was identified as the most expedient approach. This improved aircraft support scheme led to an expansion of the already planned Check Load Test to validate or provide for improvement of the existing load equations. In preparation for the Check Load Test, a practice airbag lift was performed on a surrogate aircraft, a Gulfstream II (GII). As a side note, in addition to the wing box instrumentation, the modified flap tracks were instrumented with strain gages and calibrated with known loads as reported in Ref. 5.

This paper first describes the Load Calibration Test that was performed with the aircraft resting on all landing gear, the GII Practice Airbag Lift, and then the Check Load Test that was performed with the aircraft's center of gravity (CG) supported by airbags. Load equation derivation technique and product quality will also be discussed. Table 1 highlights the sequence of tests conducted in support of the GIII wing loads calibration.

Table 1. Sequence of testing.

\begin{tabular}{|c|c|c|c|c|}
\hline \hline Timeline & Test & Aircraft & Configuration & Objective \\
\hline Feb 2013 & Live Load Test & GIII & $\begin{array}{c}\text { Supported by main } \\
\text { gear }\end{array}$ & $\begin{array}{c}\text { Assess main gear influence on } \\
\text { gages }\end{array}$ \\
\hline April 2013 & Fueling Test & GIII & $\begin{array}{c}\text { Supported by main } \\
\text { gear }\end{array}$ & $\begin{array}{c}\text { Assess main gear influence on } \\
\text { gages }\end{array}$ \\
\hline $\begin{array}{c}\text { May-June } \\
2013\end{array}$ & $\begin{array}{c}\text { Load Calibration } \\
\text { Test }\end{array}$ & GIII & $\begin{array}{c}\text { Supported by main } \\
\text { gear }\end{array}$ & $\begin{array}{c}\text { Develop multi-gage load equations } \\
\text { March 2014 }\end{array}$ Practice Airbag Lift \\
April 2014 GII & Check Load Test & GIII & $\begin{array}{c}\text { Supported by airbags } \\
\text { Supported by airbags }\end{array}$ & $\begin{array}{c}\text { Validate airbag operations on } \\
\text { surrogate GII }\end{array}$ \\
$\begin{array}{c}\text { Correct and validate } \\
\text { multi-gage load equations }\end{array}$ \\
\hline \hline
\end{tabular}




\section{Load Calibration Test}

The primary test objective was to establish an adequate database for load equation derivation by applying a set of known loads and recording strain-gage outputs. This database consists of the measured loads input and the corresponding strain-gage bridge outputs. These data were then used to derive multi-gage load equations for shear force, bending moment, and torque at each of the two measurement stations located on the left wing. A secondary objective was to collect elastic wing deflection data for GIII finite element model (FEM) comparison in preparation for ACTE.

There was a requirement by the instrumentation group to perform a repeat load case using the on-board data acquisition system (DAS). The purpose of repeating a load case was to validate the on-board DAS by comparing it to data taken using the FLL DAS. However, the onboard data system was not fully installed at the time of the load calibration testing so a separate check loading at a later date was planned to provide the required onboard data system validation. This aircraft data system validation was accomplished in the Check Load Test described later in this paper. The following sections describe how this testing was conducted. Description of the SCRAT aircraft configuration, load zones, load cases, restraint hardware, loading hardware, instrumentation, and displays and execution checklists are included.

\section{A. Aircraft Test Configuration}

The aircraft was fully loaded with about 28,000 lb of fuel all in the wings. The 1-g inertial loading of this fuel was constant throughout the load calibration test. Since the fuel weight did not vary with the applied hydraulic or shot bag loads, it was transparent to the strain-gage load equation derivation analysis performed with the test data. This fuel state provided a high gross weight which allowed large up loads to be applied without lifting the aircraft off the floor. All structural panels were installed allowing the aircraft to carry maximum test loads. The main gear was serviced to full extension, and the tires were resting on the floor. The nose gear was supported on a 20-inch tall stand. This main gear servicing and nose gear support combination caused the fuselage to rest at 1.5 deg nose down which caused the wing to be at zero inclination. The standard Fowler flaps were installed and extended aft to 10 deg to keep them out of the way. The wing surface mounted research air pressure ports were protected by tape. The wing vortex generators were covered by 2-inch thick slotted foam pads during shot bag loading.

\section{B. Calibration Loading Design}

The load zones are shown in Fig. 4, were developed using engineering judgment, and designed to cover adequate areas of the wing box outboard of the measurement stations. Some load zone design considerations were sufficient load capacity, acceptable load pad weight, ability to support adequate unique load cases for each measurement station, and limiting the amount of required loading hardware. In the preliminary stage of test plan evolution, only Zones 1 through 6 existed, and there were thoughts of inputting loads through the modified flap tracks. After further study, it was decided to drop the flap track loading due to load application challenges and add load Zones 7 and 8.

The test load cases are shown in Table 1 and were developed using engineering judgment to produce a test database that would yield high quality load equations. Considerations here included: sufficient load magnitudes while not lifting the aircraft off the floor, adequate variation in load centers resulting in sufficient unique load cases, protecting the wing skin from damage, and reasonable test execution time. The load predictions in Ref. 6 were used in combination with the lessons learned from the parametric studies reported in Ref. 7 to select applied test loads. Based on available knowledge of wing skin strength, it was decided to keep the peak footprint pressure of Zones 1 through 6 below 5 psi. The loading of Zones 7 and 8 was allowed to go up to 10 psi since the inboard skin is stronger. Most load cases were symmetric left to right, however, the mildly antisymmetric (torsionally) cases 8 and 9 were included due to the advice in Ref. 2 concerning aircraft with tip-to-tip continuous wing structure, such as the GIII. Mild down loads were produced using shot bags placed on the upper surface of the wing and are shown as negative loads in Table 2. Maximum torsion loads were produced by combining hydraulic up loads with shot bag down loads. Note that load cases 2 and 5 were not performed as they were considered to be covered by load cases 1 and 6 .

Cargo straps were used to restrain the aircraft laterally and longitudinally at both the nose and main gear. Due to the need to leave room for the forward fuselage jack, to lift the nose gear onto the 20 -inch stand, the nose tires were positioned near the aft edge of that stand. Care was taken to ensure that the aircraft could not roll off the nose stand. The restraint straps were also essential to preclude horizontal motion of the aircraft especially during high up loading which could result in putting bending moment through the hydraulic cylinders and load cells (if the aircraft drifted left or right). 
Table 2. Load cases for wing calibration tests (loads in lb).

\begin{tabular}{|c|c|c|c|c|c|c|c|c|}
\hline Load pad & 1 & 2 & 3 & 4 & 5 & 6 & 7 & 8 \\
\hline $\begin{array}{c}\text { Load case } \\
1\end{array}$ & -1000 & -1000 & -1250 & -1250 & -1500 & -1500 & & \\
\hline 2 & & -1000 & & -1250 & & -1500 & & -2000 \\
\hline 3 & 2500 & -1000 & 3500 & -1250 & 4500 & -1500 & 6500 & -2000 \\
\hline 4 & 2500 & & 3500 & & 4500 & & 6500 & \\
\hline 5 & -1000 & & -1250 & & -1500 & & -2000 & \\
\hline 6 & -1000 & 2500 & -1250 & 3500 & -1500 & 4500 & -2000 & 6500 \\
\hline 7 & & 2500 & & 3500 & & 4500 & & 6500 \\
\hline $\begin{array}{c}8 \\
\text { (Assym) }\end{array}$ & & 2500 & & 3500 & & 4500 & & 6500 \\
\hline $\begin{array}{c}9 \\
\text { (Assym) }\end{array}$ & 2500 & & 3500 & & 4500 & & 6500 & \\
\hline 10 & 2500 & & & & & & & \\
\hline 11 & & 2500 & & & & & & \\
\hline 12 & & & 3500 & & & & & \\
\hline 13 & & & & 3500 & & & & \\
\hline 14 & & & & & 4500 & & & \\
\hline 15 & & & & & & 4500 & & \\
\hline 16 & & & & & & & 6500 & \\
\hline 17 & & & & & & & & 6500 \\
\hline 18 & 2500 & 2500 & & & & & & \\
\hline 19 & & & 3500 & 3500 & & & & \\
\hline 20 & & & & & 4500 & 4500 & & \\
\hline 21 & & & & & & & 6500 & 6500 \\
\hline 22 & 1000 & 1000 & 3500 & 3500 & & & 6500 & 6500 \\
\hline 23 & 500 & 500 & 3500 & 3500 & 4500 & 4500 & & \\
\hline 24 & 500 & 500 & 3500 & 3500 & 4500 & 4500 & 5000 & 5000 \\
\hline 25 & 500 & 500 & 3500 & 3500 & 4500 & & 6500 & 6500 \\
\hline 26 & 500 & 500 & 3500 & 3500 & & 4500 & 6500 & 6500 \\
\hline 27 & 500 & 500 & 3500 & 3500 & 4500 & 4500 & 6500 & \\
\hline 28 & 500 & 500 & 3500 & 3500 & 4500 & 4500 & & 6500 \\
\hline
\end{tabular}

All hardware was designed for a factor of safety of 3.0. Additionally, all hydraulic cylinders were checked for buckling margin at peak load and maximum height. Hydraulic loading hardware generally followed the practice used in Ref. 8, except that no whiffle trees were used.

The load pads used for this test were specifically designed to fit the designated load zones of this aircraft. The load zones were designed to use the available wing box space outboard of the measurement stations and provide enough unique load cases to support coefficient derivation for up to five-gage load equations. Beside the design factor of safety of 3.0 (on strength), the stiffness of the pads was considered in the design so that the peak to average pressure ratio caused by flexibility effects would be acceptable. These considerations led to the selection of 0.5-inch thick 2024 aluminum alloy for the plates. These load plates were backed up by 4-inch deep aluminum channels. The channels were connected to the plates using 3/8-inch screws. Neoprene foam rubber was selected to line the contact side of the load pads. Samples of two different densities were obtained and tested for compressive stiffness. Neoprene was selected as the material type due to its chemical insensitivity to jet fuel and hydraulic fluid. At low load the wing surface and the load pad plate can be considered parallel planar surfaces, but at high load both become convex. It is the rubber layer that compensates for this effect of structural flexibility. The rubber density was selected to give between 1/4- to 1/2-inch squish (or compressive contraction) at max load as this amount of squish was thought to be enough to minimize the pad peak to average pressure ratio for this application. Later analysis proved this pad elastic 
compliance was adequate. The rubber was bonded to the plates using polysulfide fuel tank sealant. The resultant load pads were largely immune to the effects of any fuel or hydraulic fluid contamination as well as having appropriate strength and stiffness for testing this aircraft. Previous load pad development research is given in Ref. 9. The load pads for 7 and 8 were copies of 5 and 6 , except that 7 and 8 were given thicker rubber ( 2 inches instead of the 1.5 inches used outboard) to help keep down the peak over average pressure ratio since 7 and 8 were planned to go to about twice the load level of 5 and 6. Analysis showed that strength was not a limiting issue here. No load pads were bonded to the wing skin in consideration of test build-up and tear-down time, and since shot bags were considered adequate for the desired down loads.

\section{Hydraulic Load Application Description}

The FLL utilizes a digital 80-channel mechanical load control system (MLCS) that is comprised of a hydraulic power unit (HPU) and several hydraulic distribution carts with 8 channels of hydraulic control per cart. The host computer for the MLCS is located in the FLL control room. The control system operator creates and selects the command profiles appropriate for the test conditions. The host computer sends these profiles via Ethernet to the Real Time Front End (RTFE) computer, located in a portable cabinet on the FLL high bay floor just below the control room. The RTFE communicates to the hydraulic cart's signal conditioning cards also via Ethernet cables. The RTFE runs the real-time tasks such as function generation and safety parameter monitoring (interlocks). The major components of the hydraulic carts include solenoids and other fluid distribution valves, and transducer signal conditioning electronics and additional interfaces for controlling the servo valves to distribute controlled hydraulic pressure to the actuators. A pressure regulator for each channel on the cart allows for adjustment of HPU supply pressure on a per channel basis. Quick disconnects on the cart allow for easy attachment of hydraulic fluid supply and return hoses, to and from the HPU and to and from each hydraulic actuator. Manually-set dump valves (precision needle valves) are utilized in the fluid path to and from each actuator in the test setup to allow controlled actuator bleed-off rates in the event of an HPU shut-down.

For the GIII Wing Calibration Load Test, a total of 16 hydraulic actuators were used underneath the wings to generate uploads as defined by the test cases (see Table 1). The actuators were incorporated into load column assemblies of differing heights to allow for the fully assembled columns to remain vertical when fully retracted under the aircraft (with weight on wheels and main landing gear struts fully inflated). The load columns were secured to the floor via I-beams, jack bases, spacers, and pedestals of varying length. A load cell was affixed to the top of each actuator in the column and was used to generate the applied force signals as feedback to the load control and data recording systems. Linear resistance transducers (LRTs) are built into each actuator to provide displacement feedback to both systems. Load pads acted as the force distribution interface between the load application points and the wing surface. Spherical bearings at the load pad rod ends and contoured pins at the jack bases, allowed slight angle changes of the load columns to accommodate varying wing angle changes that occur during load application. Figure 5 shows a typical load column. Figure 6 shows a typical left-wing hydraulic load hardware set.

Two major requirements to determining column length were: 1) provide full test load application without running out of actuator stroke due to wing flex, and 2) ensure the load column was short enough at full actuator retract to fit vertically under the wings at full gear strut extension. In this way, the actuators could be mounted to the floor-mount section of the column and remain in place for the duration of the tests. An additional consideration was that this test series was to be conducted with the aircraft at near gross weight and wing tanks full of fuel, which meant allowances needed to be made for maximum wing droop. Wing droop was predicted using FEM. Due to flex calculations (also by FEM) for the wing tips and higher force applications requirements at the wing roots, it was determined that actuators capable of 32-inch extension able to deliver 2,500 lb force at estimated test stroke displacement would be used at the wing tips (positions 1 and 2). Actuators capable of 32-inch extension and 9,600 lb force at estimated test stroke displacement would be used at the mid-span positions 3 and 4. Actuators capable of 32-inch extension and 5,700 lb force at estimated test stroke displacement would be used at the mid-span positions 5 and 6 , and actuators capable of 24-inch extensions and delivering 13,500 lb force at estimated test stroke displacement would be placed at the wing root positions 7 and 8 .

All of the pads were placed on the wing surface (by manually-controlled sequential actuator extension) only once per day and held in place by a pre-load value or rest condition to mitigate pad slipping on the wing skin. Any number of test conditions could be run throughout the testing period with no additional channel setup time or pad placement requirements. Each load condition was programed with its own step time which allowed the load cases to be run in any order and quantity. The load column pads that were not applying the loads in the table were still controlled by the system, applying the pre-load 100-lb compressive (following) load, holding the pads in place on the wing skin. This use of the following loads minimized setup time for subsequent load cases. 
This test called for compression forces to be applied to the lower wing skin surfaces using hydraulic actuators, load distribution pads, and load column materials and lengths sized appropriately to achieve the force application goals of the test. The wing skin pressure limits could not be exceeded, so for the Load Calibration Test, a legacy method to protect the wing skin from overload was incorporated, utilizing the system's interlocks (automatic safety limits) and dump valves.

If there was an exceedance of 110 percent of the target value, an intermediate interlock would activate, calling a script (predetermined sequence of commands) that commanded a return to the preload condition in 50 seconds, thus using the control system to quickly and evenly unload the wings. In the event that any condition caused an exceedance of 115 percent of the predetermined target value of the test, an interlock would activate, commanding the HPU to shut off (dump). The dump valves were set closed, not tight, to allow the actuators to slowly bleed off and retract in stroke, due to the weight of the aircraft on the load pads, if a dump should occur.

During the early Load Calibration Test runs, load error interlocks were also utilized to protect the aircraft from control inaccuracies. A dump interlock was programmed if any condition caused a load application in excess of 2 percent of commanded load. If an error in excess of 1 percent commanded load was measured, an interlock was activated, and the control system would execute the script that unloaded the forces back to the preload condition.

\section{Instrumentation and Displays}

Test data was provided by the wing strain gages, load column load cells and LRTs, string potentiometers (shown in Fig. 7), and an optical photogrammetry system. FLL real-time data displays were built using the Interactive Analysis and Display System (IADS) and graphically and numerically showed real-time signals. The real-time data were also recorded using the FLL DAS for post-test analysis.

\section{E. Test Procedures}

Detailed test checklists were developed for each of the load cases to ensure that tests would not only meet the test objectives, but would also be conducted safely. The following section outlines the notional procedures used during the conduction of GIII wing loads calibration test.

\section{Pre-Test Checklist}

Prior to the execution of each load case, a pre-test checklist was followed in preparation for testing. The pre-test checklist verified proper aircraft configuration, and that each of the main systems were available and ready for test. The aircraft configuration was checked to confirm that it was secured to the test floor in accordance with the test plan. The main test systems included the mechanical load control system, the data acquisition and display systems, and the video and communication systems. The pre-test checklist also confirmed that the test area was configured to ensure the safety of test and non-test personnel.

\section{Load Case Checklists}

Multiple checklists were developed for the execution of each load case. Load cases included upload, download, and combined loads (download with upload) testing. For upload tests, load was applied to the aircraft wings using a mechanical load control system and a system of hydraulic actuators, load cells, and load pads located under each wing. The upload checklist procedures were separated into four basic sections: preliminary setup, test setup operation, loading operation, and test shutdown operation. During the preliminary setup test personnel are officially assigned to roles and responsibilities, and test safety items (hazards, emergency calls, and personnel protective equipment) were reviewed. Also during preliminary setup, the configuration of the aircraft and setup, and operational status of each test system was verified as ready for test. The test setup operation involved preparing the test area, and the data acquisition and load control systems for test. The loading operation involved extending the hydraulic actuators and preloading the load pads against the wing, followed by performing three load cycles, shown in Fig. 8, to loads prescribed by the load case, then retracting the hydraulic actuators. The test shutdown operation involved shutting down the mechanical load control and data acquisition systems, and putting the aircraft back into a safe non-test configuration.

For the download tests, load was applied to the wings by placing shot bags in load zones on the upper surface of each wing. The download checklist procedures were separated into three basic sections: preliminary setup, loading operation, and test shutdown. Similar to the upload test checklist, test personnel roles and responsibilities and test safety were reviewed during the preliminary setup section. Additionally, the preliminary setup verified that the setup and operational status of each test system were ready for test, and that the aircraft was properly configured for loading. Lastly, shot bags were positioned at inboard and outboard stations along the leading edge of each wing. The loading operation involved preparing the test area, data acquisition system, and positioning test personnel for shot bag loading the aircraft. Shot bags were then loaded onto the wings in 10-percent increments, as shown in Fig. 9, to get the correct 
wing loading for each load case. Personnel then placed shot bags on the wings in 10-percent load increments. A photo showing the maximum shot bag load is given in Fig. 10. Data were collected at each 10-percent load increment after personnel stepped off the wings, and wing oscillations had subsided. This process was repeated for unloading the wings. The test shutdown operation involved shutting down the data acquisition system and putting the aircraft back into a safe non-test configuration.

For combined loads tests, wing loading included both the use of shot bags and the mechanical load control system. The combined load checklist procedures were separated into the four basic sections: preliminary setup, test setup operation, loading operation, and test shutdown operation. Similar to the upload and download checklists previously discussed, the preliminary setup section for combined loads testing included a definition of test personnel roles and responsibilities, a review of test safety related items, a verification that test systems and the aircraft are ready for test, and the positioning of shot bags. The test setup operation involved preparing the test area and the data acquisition and load control systems for test. The loading operation was broken down into two segments, shot bag and hydraulic loading. Test personnel loaded the wings with shot bags in 10-percent load increments in accordance with the load case. Similar to the download case, data was collected at each 10-percent load increment after wing oscillations subsided. After the shot bags were loaded as shown in Fig. 11, the mechanical load control system was activated, the hydraulic actuators and load pads were raised into position, and preloads were applied to the wing lower surface. Multiple mechanical load cycles were then applied to the wings as prescribed by the load case. A photo of a combined load is shown in Fig. 12. Once the load cycles were completed, the actuators were retracted, and test personnel removed the shots bags from the wings in 10-percent load increments. Again, data were collected at each 10-percent load increment after wing oscillations subsided. The test shutdown operation involved shutting down the mechanical load control and data acquisition systems and putting the aircraft back into a safe non-test configuration.

\section{GII Practice Airbag Lift}

Once plans were being made for the Check Load Test to be expanded to include airbag support of the aircraft and some additional repeat load cases, consideration was given to doing a practice lift of some object in order to optimize safety and efficiency of test with the valuable project research test bed aircraft. AFRC had never used airbags to hold up an aircraft while test loads were applied to it, and there was a need to prove both the airbags and the procedures in regard to adequacy and safety. A well-used GII aircraft was available and was observed to be an excellent surrogate for the test bed GIII since it was very close in size, configuration, and weight. The GII practice lift plan was approved and executed. The GII contained little fuel and the remaining fuel tank volume was inerted with nitrogen gas as a safety feature in the event of some accident. The nose gear was supported the same as had been during the Wing Load Test. A reduced set of string pots were used. Similar displays and checklists were also used. This practice lift exercise proved to be a great checkout for the hardware and the procedures, and great practice for the personnel. No mechanical loads were applied to this aircraft. Pre- and post-lift inspections were performed to verify that no harm was done to the aircraft. The GII is shown configured for lift in Fig. 13 and is shown with fully inflated airbags in Fig. 14. The airbag support system, aft airbag platform, main gear restraint straps, and wheel constraint boxes (shown in Fig. 15) planned for use in the GIII Check Load Test were used in this practice lift and are described here.

\section{A. Airbag Support System Operations}

An airbag system was used to support the aircraft during the Check Load testing. The standard aircraft recovery system consisted of three airbags, each airbag with pressure relief valves designed to release at $2.5 \mathrm{psi}$, a control manifold, and interconnecting hoses. Each bag had a footprint of $7.5 \mathrm{ft}$ by $6.5 \mathrm{ft}$ and could extend up to $6 \mathrm{ft}$. The bags had a lift capacity of 24,000 lb. The airbag system also incorporated an air source capable of supplying $30 \mathrm{psi}$ through a 3/4-inch hose attachment. During our testing one airbag was placed under each wing at the root leading edge, slightly forward of the center of mass of the aircraft. One airbag was placed at the rear fuselage to stabilize and balance the lift and prevent nose up pitch. These airbags can be seen in Fig.13. Because this system was designed for field aircraft recovery, it was not required to be completely air tight, thus constantly leaked. This issue had to be addressed when wing loads were applied to the wings with the hydraulic system.

In order to address the leak issue and provide airbag pressure control, FLL personnel modified the airbag inflation system. A new design was incorporated that provided individual pressurization and relief control for each airbag. This design also allowed the use of shop air as the supply source. Multiple airbag controller manifolds, one shown in Fig. 16, consisted of a pressure regulator 0-140 psi, a 25 psi manifold pressure relief valve, a 0-30 psi manifold pressure gage, and two ball valves (supply/dump). Operation of this system required a DAS display monitor (shown in Fig. 17) so that the airbag operator could monitor and adjust pressures at the airbags based on the aircraft height at the main wheels, nose wheel, tail cone, and wing tips. 
System control was straightforward during initial inflation up to airbag contact with the aircraft lower surface. The supply pressure regulators for each airbag was set to 20 psi, and each supply ball valve was opened to provide airflow into its corresponding airbag. Once an airbag made contact with the aircraft, the supply ball valve was closed, and the airbag was adjusted in relation to the aircraft for final placement. Then a small amount of air was added to the airbag. This added volume brought the bag surface to the aircraft skin, and the surface friction kept the bag placement correct. When sufficient contact friction was achieved, the ball valve was closed. These steps were repeated for each airbag.

Before lifting the aircraft, the supply pressure regulators were set to 10 psi because large volumes of air (to initially inflate the airbags) were no longer needed. Slight increases in pressure were required to lift the aircraft from this point. The lower pressure also allowed for finer control with the ball valves. To lift the aircraft, all supply ball valves were slightly opened and the airbags were increased in pressure simultaneously. Personnel were placed at each airbag to verify that proper airbag contact with the aircraft was maintained. The airbag system operator monitored the data display and adjusted the ball valves as necessary to ensure that the aircraft was being lifted evenly and to the correct height required for wing load testing.

When the aircraft was at the correct pitch and roll, and the main wheels were within the target height window (between 0 and 4 inches off the ground), all valves were closed, and air leak-rate became the time constraint. To achieve a clean data run, the hydraulic loading profile needed to be started, and the load needed to achieve the maximum test load before the main wheels came back into contact with the ground. As the hydraulic actuators applied load to the aircraft, airbag force was supplemented, causing a tendency for the aircraft to rise. During the loading profile, the operator had to observe and maintain aircraft altitude and attitude. Pressure in the airbags had to be relieved in order to remain within the target height and angle constraints. This pressure reduction was accomplished by appropriately adjusting the dump valves. For maximum force applications, the hydraulic loading ramp rate had to be low in order to not exceed the deflation rate of the airbags and cause an excessive height of main wheels above the ground. At the end of a test run the dump valves were closed in preparation for the next pressurization cycle and test run.

\section{B. Airbag Supporting Hardware Description}

The aft platform was provided to raise the aft airbag to reach the intended aft fuselage contact area and adjust the airbag angle to be approximately parallel with the local fuselage surface angle. Assumptions were made regarding how the aft bag would wrap around the fuselage laterally to determine the height required. The fuselage contact area was selected based on the general guidance provided by the aircraft maintenance manual and the presence of protruding vent tubes and blade antennae. The available surface area turned out to be just slightly bigger than the bag area.

The wing load test used restraint straps from the main gear to the floor, however, for this test series it was desired to have the straps apply load close to horizontally so as not to provide any vertical loads into the main gear since that was the whole purpose of the airbag use. There was very little tolerance for aircraft horizontal motion during loading operations as this could result in putting bending moment through the load columns. As the main gear tires would no longer be providing any lateral restraint the main gear straps became even more important. In order to support the other end of the straps, stanchions were designed and assembled. The stanchions were located away from the wings so that in the event of a main gear strut seal failure, there would be no risk of a wing impacting a stanchion. Because of the angle of the fuselage at the aft bag contact area, it was known that there would be a forward vector component of up to several hundred pounds that would occur as the aft bag reached its max pressure. To compensate for this forward thrust load, the aft strap on each main gear was doubled. Turnbuckles were added in series with the straps to provide for fine tuning of the strap preloads. After adjusting the preload on all the straps the aircraft remained acceptably centered during lifting and loading operations.

Two wheel box structures (Fig. 15) surrounded the main gear on four sides and were designed as a secondary measure to prevent lateral movement of the aircraft in case the restraining cargo straps failed. The structures were assembled using C9 X 20 steel channels fastened with grade 8 hardware. The assemblies were further reinforced with steel channel members. Plywood spacers were used inside to minimize gaps between the sides of the structures and the wheels. The wheel box structures allowed for a 1.5-inch gap on all sides of the main gear to prevent the main gear from coming in to contact with the wheel boxes during wing loading. Each wheel box was clamped to the floor in four locations. 


\section{GIII Check Load Test}

The primary objective of this test was to establish an adequate database for validating or correcting existing load equations by applying a set of known loads and recording strain gage outputs while main landing gear are isolated. This test series was essentially a down-sized (fewer load cases and less load) Wing Load Test, but with the added feature of the airbags supporting the aircraft without the main gear touching the floor. This aircraft test setup can be seen in Figs. 18 and 19. The string potentiometer layout used in this test can be seen in Fig. 20. The secondary objectives were to collect floated strain gage zeroes, check for aileron binding under load, and finally to create corresponding databases using the FLL DAS and the onboard data system to support validation of the GIII data system. These data were successfully recorded.

\section{A. Check Load Test Products}

The individual strain gage zero (or unloaded) values are important since these are used in analytically creating the load equation zero offset values. Ideally, the final product load equations will indicate zero load while the structure at the load measurement station is at zero stress. This result often cannot be directly accomplished from measured data since the structure is under the effect of gravity. In theory one could place the aircraft at zero gravity (and of course zero airspeed) and simply record the strain gage outputs, but this option is not available. One practical technique for removing the effect of gravity is to calculate the shear force, bending moment, and torque due to the known mass outboard of the measurement station and putting those values in the respective load equations as zero offsets. This technique was applied in this calibration effort, but it was also understood along the way that the main gear load influence also needed to be accounted for. Therefore, recording the strain gage readings while the aircraft was supported by the airbags was an important objective.

The outboard edges of the new flap system are in proximity to the inboard edges of the ailerons. This close relationship motivated an interest in taking advantage of this opportunity to check for any indications that this new trailing edge configuration might interfere with the operation of the ailerons under a loaded wing condition. While the flight controls are hydraulically assisted and not reversible, when the aircraft hydraulic power is off (as was the case during this ground test) changes in mechanical friction or binding can be sensed during manual control sweeps of the yoke performed by a flight controls engineer seated in the pilot's seat. To aid in detecting any surface binding a camera was placed just aft of the wing trailing edge looking at the gap between the aileron and the new flap. The maximum load case was performed for the collection of strain gage calibration data with the cockpit closed and unoccupied. The cockpit door was kept open during the binding check load run to allow emergency egress if needed. The engineer wore a wireless headset and was in the communications loop. None of the control sweeps including the one performed during peak load produced any sensation of control interference or binding.

This same max load case was repeated with the strain gage data routed through the onboard data system. The data from that system was displayed and recorded at an instrumentation monitoring station outside the aircraft. This aircraft data base and the corresponding FLL DAS data base were compared, and it was found that they agreed. This comparison was done as partial validation of the aircraft data system.

\section{B. Calibration Loading Design}

The GIII contained about 4,000 lb of fuel during this test, and the remaining fuel tank volume was inerted with nitrogen gas as a safety feature for the event of some accident. It was desired to keep the aircraft gross weight low to stay within the capacity of the three airbags. The nose gear was supported the same as it had been during the Wing Load Test. The airbag support system, aft airbag platform, main gear restraint straps, and wheel constraint boxes tested in the GII Practice Lift were used here. Data were monitored for safe test execution at a station near the nose of the aircraft as shown in Fig. 21. The Wing Check Load test included 14 load cases, or conditions, as seen in Table 3 below. Note that load case 14 was used three separate times - once for FLL DAS data, once for a corresponding database through the aircraft data system, and a third time for the aileron binding check under wing load. 
Table 3. Load cases for wing check load tests (lb).

\begin{tabular}{|c|c|c|c|c|c|c|c|c|c|c|c|c|c|c|}
\hline \hline $\begin{array}{c}\text { Load } \\
\text { case }\end{array}$ & 1 & 2 & 3 & 4 & 5 & 6 & 7 & 8 & 9 & 10 & 11 & 12 & 13 & 14 \\
\hline $\begin{array}{c}\text { Load } \\
\text { pad 4 }\end{array}$ & 3500 & & & & & 3500 & 3500 & & & 3500 & & 3500 & 3500 & 3500 \\
\hline $\begin{array}{c}\text { Load } \\
\text { pad 5 }\end{array}$ & 4500 & & & & 4500 & & 4500 & 4500 & 4500 & & & & 3500 \\
\hline $\begin{array}{c}\text { Load } \\
\text { pad 6 }\end{array}$ & & 4500 & & & & 4500 & 4500 & & 4500 & & 4500 & & 3500 \\
\hline $\begin{array}{c}\text { Load } \\
\text { pad 7 }\end{array}$ & & & 6500 & & & & & 6500 & & 6500 & & 6500 & 3500 \\
\hline $\begin{array}{c}\text { Load } \\
\text { pad 8 }\end{array}$ & & & & 6500 & & & & & & 6500 & 6500 & 6500 & 3500 \\
\hline \hline
\end{tabular}

\section{Hydraulic Load Application Description}

For the GIII Wing Check Load Test with airbags; 10 hydraulic actuators, each capable of 32-inch extension, were used underneath the wings to generate uploads as defined by the test plan. The actuators were incorporated into assemblies of differing heights to allow for the fully assembled columns to remain vertical when fully retracted under the aircraft (with weight on wheels and main landing gear struts fully inflated). The load columns were secured to the floor via I-beams, jack bases, spacers and pedestals of varying length, as was accomplished a year earlier during the GIII Load Calibration Test.

Additional considerations for determining column length specific to the Check Load Test requirements were to provide full load application capability without running out of actuator stroke, with the aircraft lifted on airbags (weight off wheels). Unknowns such as airbag lift displacement changes as airbags bled off (bleed-off rate and associated height changes) and as weight was transferred off of airbags onto the load columns during the loading profile, had to be considered. Ideally, the airbag leak rate needed to be matched by the hydraulic loading rate to achieve minimum aircraft elevation change during the hydraulic loading portion of the profile.

It was determined during the Load Calibration Test that if there was an HPU shut-down under load due to any condition that caused an exceedance of the force limit interlock, it was desirable for the outer six load columns, three on each wing near mid-span, to quickly bleed off the hydraulic fluid in those cylinders. Opening the dump valves on the outer six actuators accomplished this goal. This lesson learned was applied to this test. By operating with the inner four channels' dump valves closed, those actuators were not allowed to bleed off after an HPU pressure dump. This method allowed the aircraft weight to transfer to the inner four wing root load pads, two at each wing root, which had adequate skin pressure margin to support the aircraft.

As in the Load Calibration Test, two values of error interlocks were again utilized to protect the aircraft from control inaccuracies, but in the Check Load Test the error margin was opened to $245 \mathrm{lb}$ of commanded load. This setting allowed the controller to bring the loads back down to pre-load using an expedited step time without exceeding the error interlock value that would force an HPU dump. Step time was set to 100 seconds. Pre-load condition values were again set for all actuators to apply $100 \mathrm{lb}$ compression force.

\section{Test Procedures}

Detailed test checklists were developed for each of the check load cases to ensure that tests would not only meet the test objectives, but would also be conducted safely. This section outlines the notional procedures used during the conduction of GIII Check Load Test.

\section{Pre-Test Checklist}

Prior to the execution of each load case, a pre-test checklist was followed in preparation for testing. The pre-test checklist verified proper aircraft configuration, and that each of the main systems were available and ready for test. The aircraft configuration was checked to confirm that restraint hardware was in place in accordance with the test plan. The main test systems included the mechanical load control system, airbag lift system, the data acquisition and display systems, and the video and communication systems. The pre-test checklist also confirmed that the test area was properly configured to ensure the safety of test and non-test personnel. 


\section{Airbag Lift Checklist}

Airbag lift test procedures were developed for verifying the operation of the airbags, assessing the stability of the aircraft while lifted on airbags, and determining the airbag leak rate. The procedure was separated into three basic sections: preliminary setup, test operation, and test shutdown operation. During the preliminary setup, test personnel were officially assigned to roles and responsibilities, and test safety items (hazards, emergency calls, and personnel protective equipment) were reviewed. Also during preliminary setup, the configuration of the aircraft and setup, and operational status of each test system was verified as ready for test. The test operation included procedures for lifting the aircraft using airbags and for performing the stability and leak rate tests while the aircraft was lifted on airbags. During the airbag lift operation, the airbags were incrementally inflated until the main gear wheels lifted off the ground to a prescribed height. Once the wheels were off the ground a stability test was performed to make a subjective assessment of the aircraft lateral stability. Test personnel gently rocked the aircraft by pushing up on the wing tips. A leak rate test was then performed by shutting off the air supply line and timing how long it took for the wheels to come into contact with the ground from the prescribed height. The test shutdown operation involved deflating the airbags, shutting down the data acquisition system, and putting the aircraft back into a safe non-test configuration.

\section{Load Case Checklists}

Checklists were developed for the execution of each load case. The descriptions of the preliminary setup and test setup operation are the same as what was described in the airbag lift test procedures as previously mentioned. The test setup operation involved preparing the test area, and the data acquisition and airbag systems for load testing. During the test setup operation, the airbags were inflated to the pressure required to lift the aircraft main landing gear wheels off the ground. A leak check was then performed to determine the leak rate for the test configuration.

Once the leak check was complete, load was applied to the aircraft wings using a mechanical load control system and a system of hydraulic actuators, load cells, and load pads located under each wing. The test procedures were separated into five basic sections: preliminary setup, test setup operation, airbag lift operation, loading operation, and test shutdown operation. The descriptions of the preliminary setup and test setup operation are the same as what has been previously described. The test setup operation involved preparing the test area and the data acquisition, airbag, and load control systems for test. During the test setup operation, the airbags were inflated to a pressure to lift the aircraft main gear wheels off the ground after which a leak rate test of the airbags was performed to determine the leak rate for the test configuration. After the main gear wheels re-contacted the ground, the hydraulic system was turned on, and the actuators were extended so that the load pads preloaded the wing. Once all the load pads were in position and the preloads had been applied, the airbags were inflated until the main gear wheels cleared the ground by a predetermined height. After the aircraft was in a stable lifted configuration, the loading operation was initiated. The loading operation involved performing multiple load cycles to the loads prescribed by Table 3 . The airbags were manually vented to control the wheel height during the load increase. It was not a test requirement to control the wheel height during the unload. After the load cycles were completed, the actuators were retracted and the preloads removed. The test shutdown operation involved shutting down the mechanical load control and data acquisition systems, deflating the airbags, and putting the aircraft back into a safe non-test configuration.

\section{Calibration Analysis}

\section{A. Raw Data Analysis}

Data were compiled from 42 separate load cases. Cases 1 through 28 were recorded during the Load Calibration Test with the aircraft supported on the main gear, and the remaining cases were derived from the Check Load Test and were recorded with the aircraft supported on airbags. Each load case contained applied load data from the 8 left wing hydraulic actuator load cells and the 32 left wing strain gages. Load cases containing shot bag loading were handled by modifying the associated actuator load cell column to represent the additional shot bag load. The load data were specified in units of pounds. The strain gage data were specified in units of $\mathrm{mV} / \mathrm{V}$ by taking the strain output voltage and dividing by the 10 -volt excitation voltage.

The data were reviewed and noise level was assessed. Multiple load cycles were applied for each load case, and second cycle was chosen for load calibration regression analysis. The increasing load ramp slope is of most interest because the load equation intercepts are calculated once the load equations are selected. A uniform number of data points from each load case were selected, which prevented any one load case from over biasing the load equations. One hundred data points from each load case were selected and uniformly spaced along the load ramp. The increasing load ramp was selected because flight monitoring schemes typically focus only on the buildup of loads during a maneuver. The unloading of a structure after a maneuver peak is complete is typically less of a concern. Ninety-five percent of the load profile was available for load equation derivation due to the exceptional data quality. 


\section{B. Calculation of Bending and Torque Arms}

The bending and torque arms were calculated by laser scanning the load pad centroids into the aircraft (fuselage reference frame) coordinate system. The load pad centroids were then translated into the wing reference plane for load equation derivation for rear beam stations (RBS) 152 and 343. The calculated bending and torque arms for the 8 load pads are shown in Table 4.

Table 4. Bending and torque arm lengths shown in inches.

\begin{tabular}{|c|c|c|c|c|}
\hline \hline Load pad & $\begin{array}{c}\text { Bending arms } \\
\text { RBS152 }\end{array}$ & $\begin{array}{c}\text { Bending arms } \\
\text { RBS343 }\end{array}$ & $\begin{array}{c}\text { Torsion arms } \\
\text { RBS152 }\end{array}$ & $\begin{array}{c}\text { Torsion arms } \\
\text { RBS343 }\end{array}$ \\
\hline 1 & 331.9 & 119.4 & -11.7 & -11.7 \\
\hline 2 & 326.1 & 113.6 & 9.6 & 9.6 \\
\hline 3 & 285.3 & 72.8 & -14.5 & -14.5 \\
\hline 4 & 282.7 & 70.1 & 11.8 & 11.8 \\
\hline 5 & 237.4 & 24.9 & -16.8 & -16.8 \\
\hline 6 & 234.2 & 21.7 & 14.3 & 14.3 \\
\hline 7 & 45.7 & 0.0 & -37.8 & 0.0 \\
\hline 8 & 31.6 & 0.0 & 35.7 & 0.0 \\
\hline
\end{tabular}

\section{Load Case Organization}

The load cases were grouped into 4 groups for the derivation of the load equations as shown in Table 5 . The load case groups determine which cases get analyzed during the multi-linear regression analysis. It is important that the correct load cases are chosen or the load equations will not represent the load experienced in flight. Groups 1 and 2 were associated with wing RBS 152, and load case groups 3 and 4 were associated with wing RBS 343. Load case groups 1 and 3 represented loads applied while the aircraft was supported on gear, while load case groups 2 and 4 contained applied loads from the aircraft supported off of the gear on airbags. It was important that the load cases from the two different load calibration tests not be combined. Due to the influence of the gear, the multi-linear regression would not be able to differentiate between applied actuator load and the influence of the gear. A few cases were left out of each group for independent check loading cases. These independent check cases highlight the effects of main gear influence.

Table 5. Wing load test equation derivation cases.

\begin{tabular}{|c|c|c|c|c|c|}
\hline \hline \multicolumn{7}{|c|}{ G-III wing load test EQDE cases } \\
\hline EQDE_case & RBS & Gages & Pads & Load case & Check case \\
\hline 1 & 152 & $1-16$ & $1-8$ & $1,3,6,12,13,14,15,16,17,18,19,20,21,22,23,24,26,27,28$ & $4,7,10,11,25$ \\
\hline 2 & 152 & $1-16$ & $4-8$ & $31,33,34,35,36,37,38,40,41,42,43,44$ & 32,39 \\
\hline 3 & 343 & $17-32$ & $1-8$ & $1,3,6,12,13,14,15,18,19,20,22,23,24,26,27,28$ & $4,7,10,11,25$, \\
\hline 4 & 343 & $17-32$ & $4-8$ & $31,33,36,37,38,40,42,43,44$ & 32,39 \\
\hline \hline
\end{tabular}

\section{Equation Derivation Method}

Derivation of the wing load equations were accomplished through a least squares fit of the applied load and strain gage data as described in Ref. 10. The EQuation Derivation (EQDE) 3.04 program was utilized in deriving the load equations. EQDE was developed over the last 40 years at the NASA AFRC. Multiple programs have used EQDE for derivation of flight load equations. EQDE is written in American National Standards Institute (ANSI) standard Fortran 77. EQDE 3 has the ability to do an exhaustive search, thereby facilitating the consideration of every possible load equation combination for a certain number of strain gages. Load equations with 2, 3, 4, and 5 gages were assessed for suitability. As expected, the larger the number of gages used, the smaller the error. Using a large number of gages in an equation has the potential for introducing extra noise into the overall derived load equation. The exhaustive search option was used to derive load equations for all possible gage combinations without needing to pick and choose individual sets. 


\section{Calibration Results}

The completion of the aircraft on airbag load calibration test gave insight into the influence of the main landing gear into the load equations. Figure 22 shows the differences between the aircraft on gear load test and the aircraft on airbag test.

The top three load equations were chosen based on the following criteria.

- The top three best equations in each set were selected based on calculated root mean square (RMS) errors.

- Equations were selected based on having gage redundancy so that if a gage fails in flight, an independent backup equation can be selected for monitoring.

- The equations should produce 5 percent or better for the chosen validation check cases.

- The calculated load from the second and third equations should fall within a 5-percent band with that of the primary equation at peak vertical acceleration.

A total of 80 load equations were derived for each shear force, bending moment, and torque measurement at each wing station. The 80 equations consisted of the best 20 load equations (lowest RMS error) for 2, 3, 4, and 5 gage combinations. The final load equations were based on a combination of the aircraft on gear and aircraft on airbag test data. Due to the large effect of the main gear on the strain gages at wing RBS 152, the load equations were derived from the aircraft on airbag load cases. The outboard station 343 had minor effects from the main gear influence, which allowed the aircraft on gear load cases to be used for the derivation of the RBS 343 shear force and bending load equations. There were noticeable effects from the main gear in the outboard 343 station torque load equations, and so the aircraft on airbag load cases were used in the derivation of the RBS 343 torque equations.

Table 6 below shows the RMS errors for the wing RBS 152 independent check cases for the 3 selected flight equations. As expected, the aircraft on gear independent check cases have large errors for the torque equations. However, the RMS errors for the aircraft on airbag check cases all have small errors for the shear force, bending and torque derived equations. This low error level confirms two things. The equations have been verified using independent check cases, and the equations have minimal main gear influence.

Table 6. Summary of load equation RMS errors for RBS 152.

\begin{tabular}{|c|c|c|c|c|}
\hline & \multicolumn{4}{|c|}{ Flight equations RBS 152, percent } \\
\hline Eq. no. & SHR & BND & TRQ & \\
\hline 1 & 0.51 & 0.56 & 10.21 & \multirow{3}{*}{$\begin{array}{c}\text { Check case from load calibration } \\
\text { test }(4,7,10,11,25)\end{array}$} \\
\hline 2 & 1.09 & 0.28 & 5.14 & \\
\hline 3 & 2.03 & 0.45 & 25.62 & \\
\hline 1 & 0.40 & 0.50 & 1.27 & \multirow{3}{*}{$\begin{array}{l}\text { Check case from check load test } \\
\qquad(32,39)\end{array}$} \\
\hline 2 & 0.28 & 0.37 & 1.66 & \\
\hline 3 & 0.26 & 0.36 & 2.12 & \\
\hline
\end{tabular}

The same process was undertaken for wing RBS 343, the results of which are shown in Table 7. Again, large errors are observed in the torque equations for the aircraft on gear load cases, while the shear force and bending cases have acceptable errors. Aircraft on airbags check cases 32 and 39 were then assessed. The torque errors are small, but noticeably large errors are observed in the bending load equations. This large error can be attributed to check cases 32 and 39 having relatively small bending moments which leads to a larger than acceptable error. When a larger check case such as 37 is assessed, the resulting errors in bending are smaller, and the equations are deemed acceptable. 
Table 7. Summary of load equation RMS errors for RBS 343.

\begin{tabular}{|c|c|c|c|c|}
\hline & \multicolumn{4}{|c|}{ Flight equations RBS 343, percent } \\
\hline Eq. no. & SHR & BND & TRQ & \\
\hline 1 & 0.61 & 1.89 & 7.77 & \multirow{3}{*}{$\begin{array}{c}\text { Check case from load calibration } \\
\text { test }(4,7,10,11,25)\end{array}$} \\
\hline 2 & 0.65 & 0.95 & 6.69 & \\
\hline 3 & 0.87 & 1.09 & 57.40 & \\
\hline 1 & 0.50 & 7.38 & 1.28 & \multirow{3}{*}{$\begin{array}{l}\text { Check case from check load test } \\
\qquad(32,39)\end{array}$} \\
\hline 2 & 1.65 & 5.82 & 0.97 & \\
\hline 3 & 0.78 & 9.10 & 3.55 & \\
\hline 1 & 0.55 & 1.97 & 0.64 & \multirow{3}{*}{$\begin{array}{l}\text { Check case from check load test } \\
\text { (37) }\end{array}$} \\
\hline 2 & 0.85 & 3.04 & 0.56 & \\
\hline 3 & 2.46 & 3.60 & 2.32 & \\
\hline
\end{tabular}

\section{Conclusions}

In preparation for a flight research program with the ACTE flap on the SCRAT GIII aircraft a series of ground load tests were performed. The test aircraft was instrumented with a total of 32 strain gages on the port side wing with the intention of measuring wing shear force, bending moment, and torque at two key wing stations. The aircraft was initially ground load tested while resting on all three landing gear. Twenty-six single point and distributed load cases were applied using a combination of hydraulic load columns and shot bags on eight loads zones on each wing. Additional analysis was performed indicating that variable load reactions communicated to the aft wing box, though the main landing gear was corrupting some of the calibration data. It was determined that repeating a subset of the load cases while supporting the aircraft off the main gear using aircraft lift airbags would correct the data base. A practice lift of a GII aircraft was performed in preparation for the GIII lift. This practice lift exercise validated the intended lift procedure and provided crew practice. This crew practice with the GII enabled the GIII airbag lift operations, while test loading the wing, to execute smoothly. The GIII was then load tested while supported by the airbags. Sixteen load cases were applied. Additionally, floated strain gage zeroes were collected, the aircraft data system was validated, and a check was performed for aileron binding under a loaded wing condition. No binding was found. The floated strain gage zeroes were essential for determining the zero intercepts for the flight load equations. Baseline and post-test structural inspections verified that neither the GII nor GIII aircraft were damaged during the ground tests. The multi-gage load equation derivation was successful and yielded a family of accurate load equations using various combinations of strain gages.

\section{Acknowledgments}

The authors express appreciation for the work of Glen Crampton in performing design and stress analysis, Aaron Rumsey in the fabrication of the aft airbag support ramp and oversight of much of the test setup work, and for the NASA AFRC FLL team in the excellent execution of the challenging test procedures.

\section{References}

${ }^{1}$ Baumann, E., Hernandez, J., and Ruhf, J., “An Overview of NASA's SubsoniC Research Aircraft Testbed (SCRAT),” AIAA-2013-5083, 2013.

${ }^{2}$ Jenkins, J. M., and DeAngelis, V. M., "A Summary of Numerous Strain-Gage Load Calibrations on Aircraft Wings and Tails in a Technological Format," NASA TM-4804, 1997.

${ }^{3}$ Jenkins J. M., and Kuhl A. E., "A Study of the Effect of Radical Load Distributions on Calibrated Strain Gage Load Equations," NASA TM-56047, 1977.

${ }^{4}$ National Aeronautics and Space Administration Armstrong Flight Research Center, Flight Loads Laboratory, URL: http://www.aeronautics.nasa.gov/atp/facilities/fll/index.html [Cited 13 November 2014]. 
${ }^{5}$ Miller, E., Holguin, A., Cruz, J., and Lokos, W., "Strain Gage Load Calibration of the Wing Interface Fittings for the Adaptive Compliant Trailing Edge Flap Flight Test," AIAA- 2014-0277.

${ }^{6}$ Cruz, J., "Wing Loads Analysis for Adaptive Compliant Trailing Edge Experiment to be flown on AFRC Gulfstream GIII N804NA," 804-001A-PROC-119.00, (to be published).

${ }^{7}$ Lokos, W. A., and Stauf, R., "Strain-Gage Loads Calibration Parametric Study,” NASA/TM-2004-212853, 2004.

${ }^{8}$ Lokos, W. A., Olney C. D., Chen, T., Crawford, N. D., Stauf, R., and Reichenbach, E. Y., "Strain gage loads calibration testing of the active aeroelastic wing F/A-18 aircraft," NASA/TM-2002-210726, 2002.

${ }^{9}$ Crawford, N. D., "Load Pad Development for Research Aircraft Wing Strain Gage Loads Calibration Test," 2002 SEM Annual Conference \& Exposition on Experimental and Applied Mechanics, SEM 2002-211, 2002.

${ }^{10}$ Skopinski, T. H., Aiken, W. S. Jr., and Huston, W. B., "Calibration of strain-gage installations in aircraft structures for the measurement of flight loads," NACA Report 1178, 1954. 


\section{Figures}

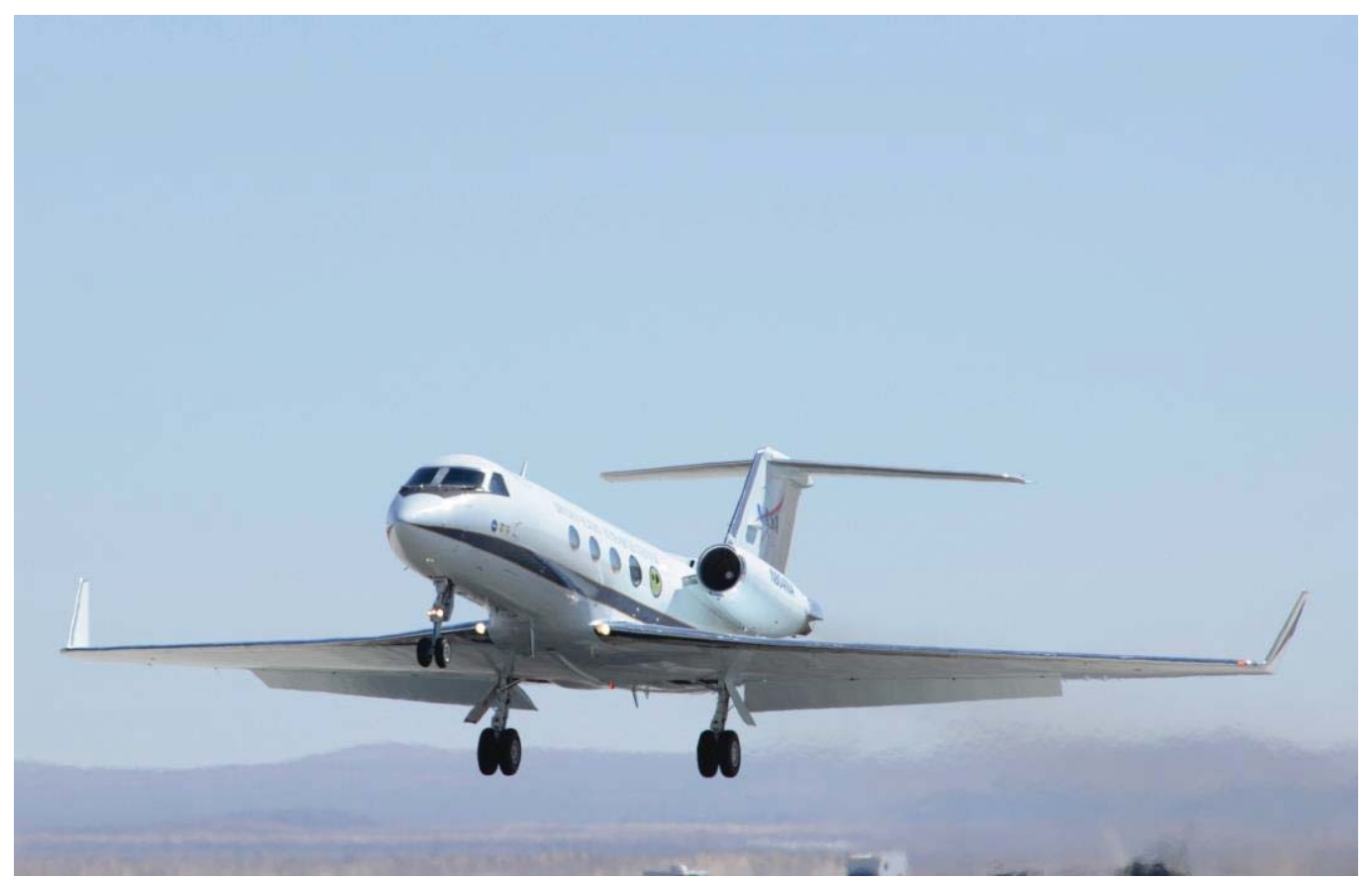

Figure 1. Photo of the SCRAT G-III test aircraft (with original Fowler flaps).

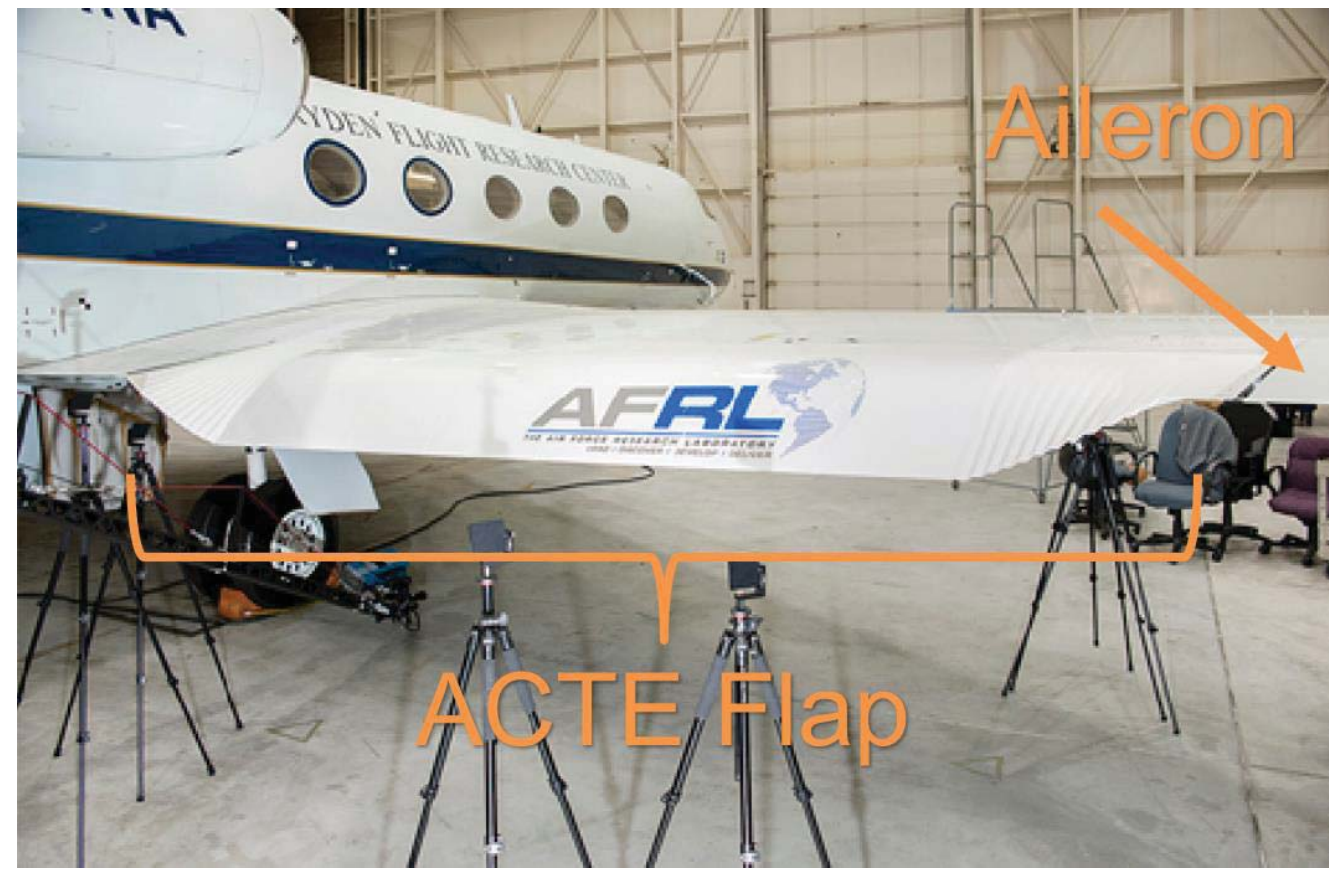

Figure 2. Photo of the ACTE flap. 


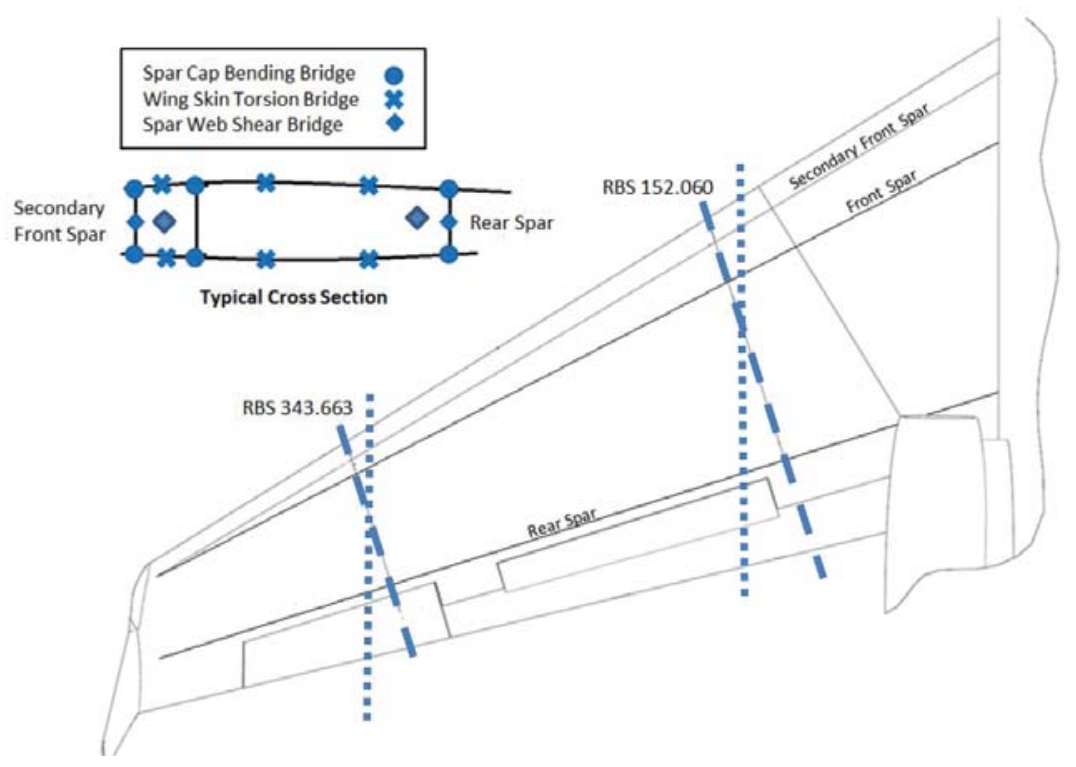

Figure 3. Wing strain gage locations.

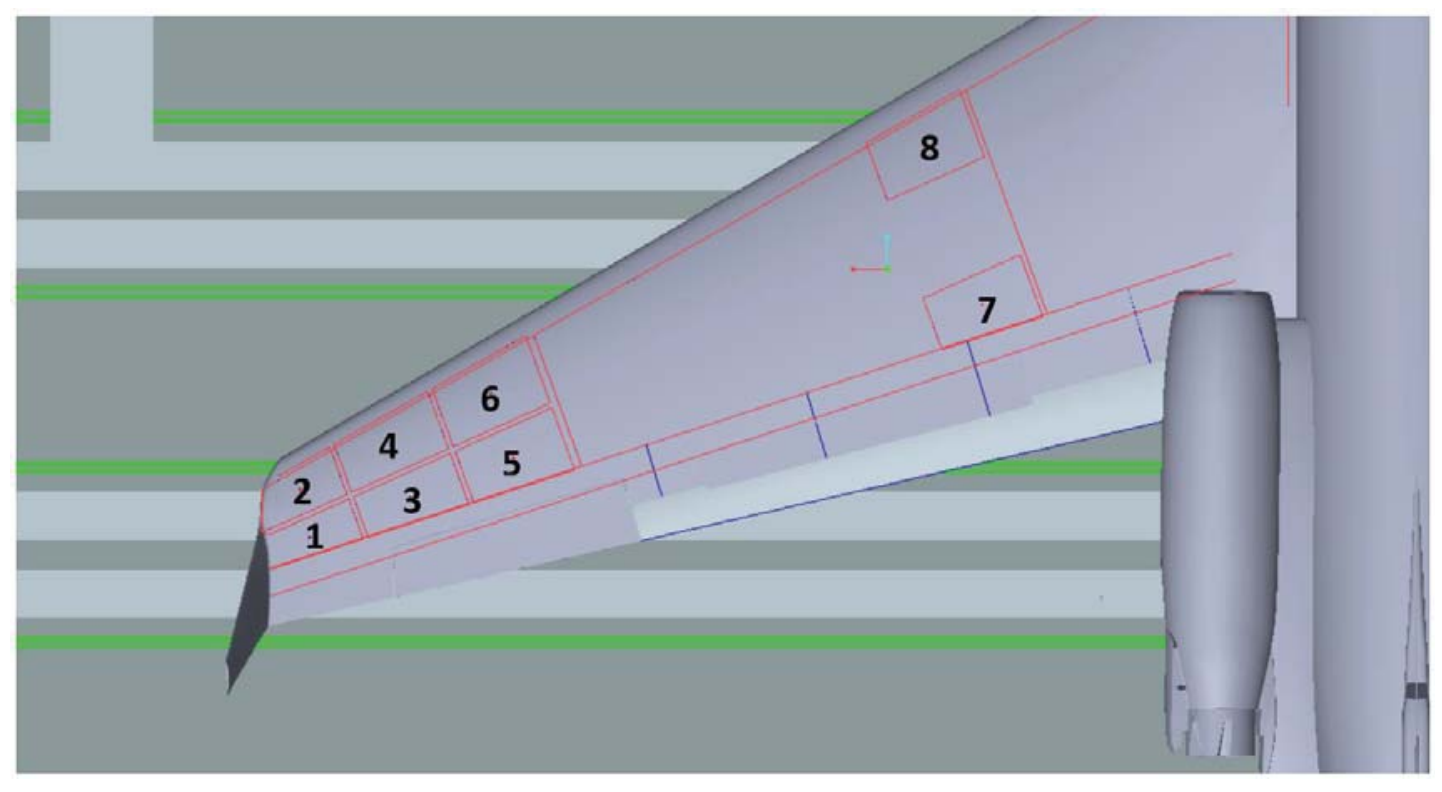

Figure 4. Wing load zones. 


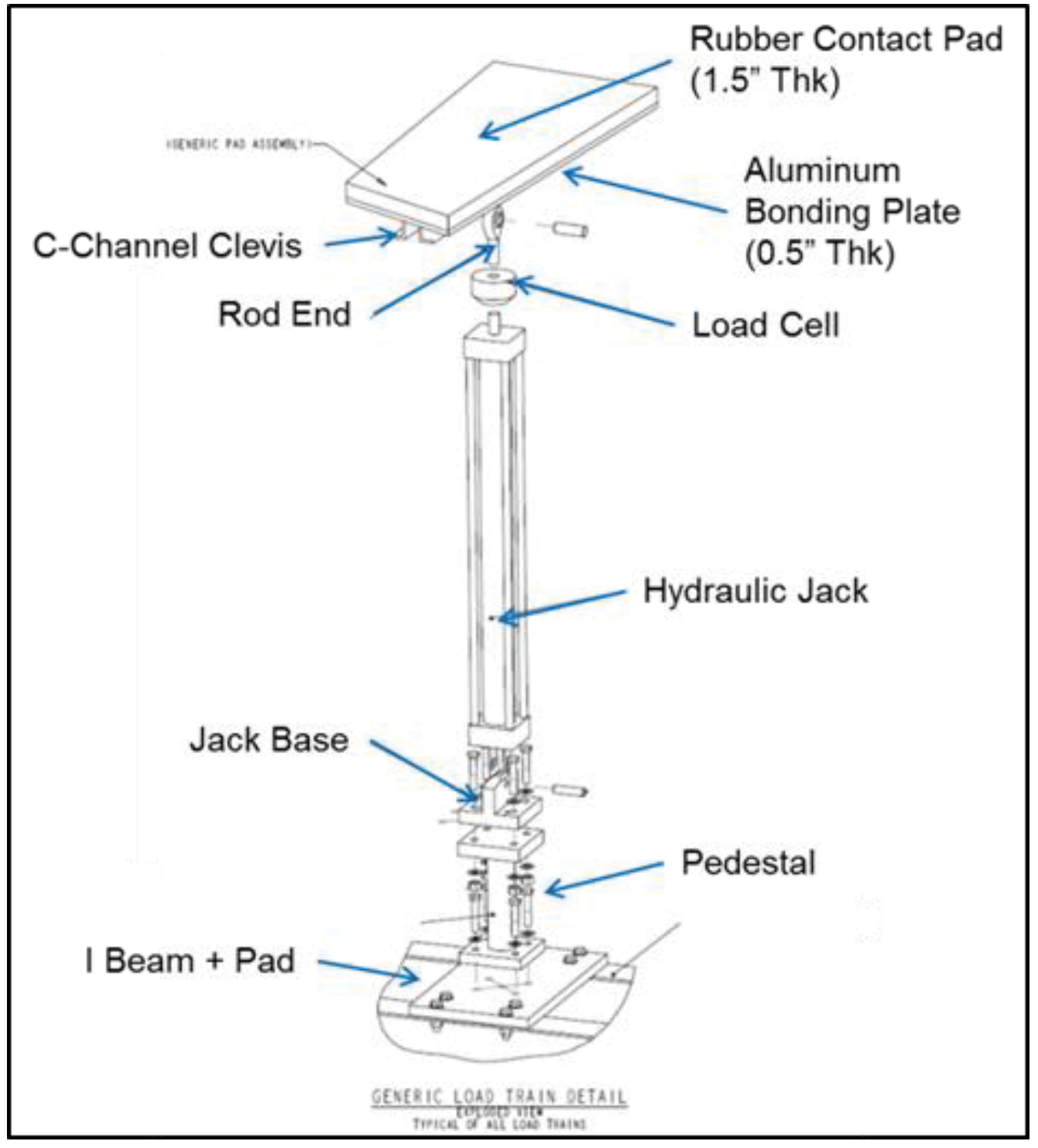

Figure 5. Drawing of typical hydraulic load column. 


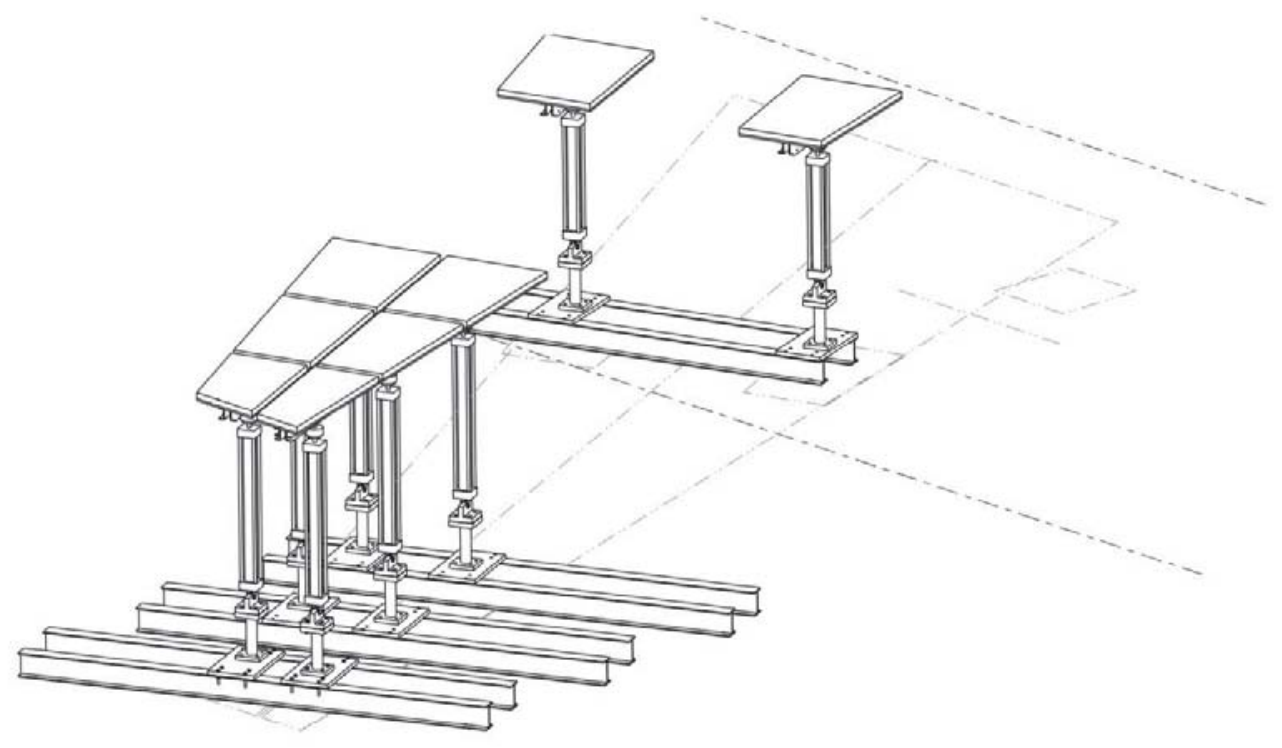

Figure 6. Drawing of port side loading hardware.

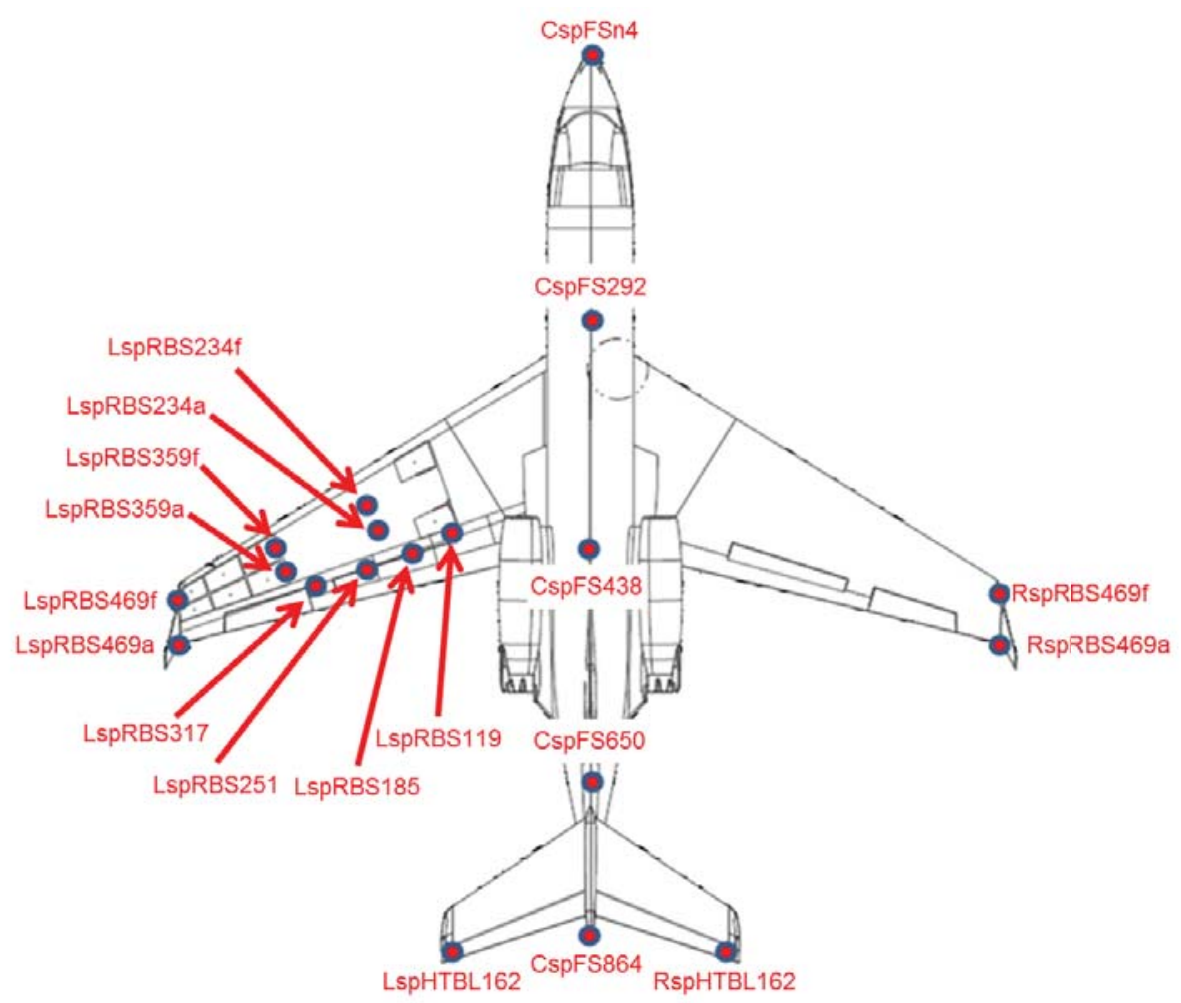

Figure 7. String potentiometer locations. 


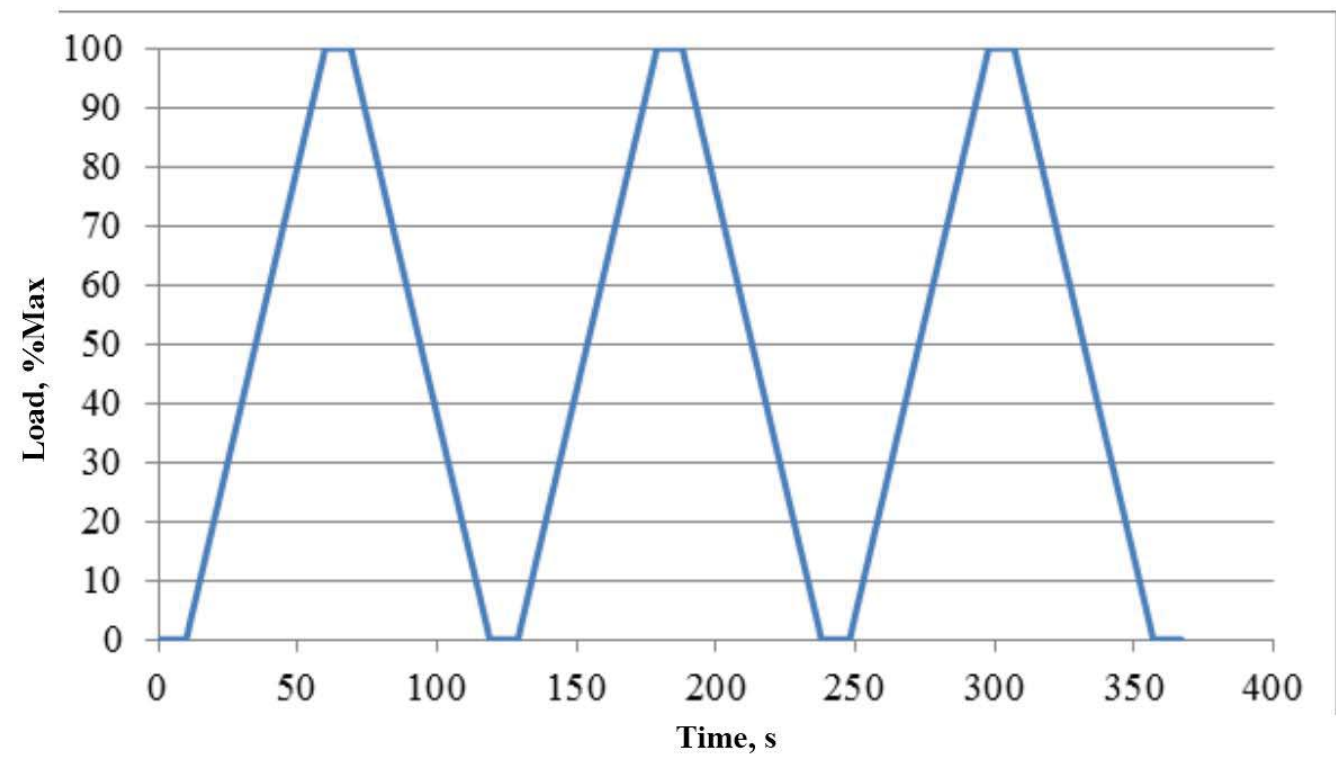

Figure 8. Hydraulic load profile.

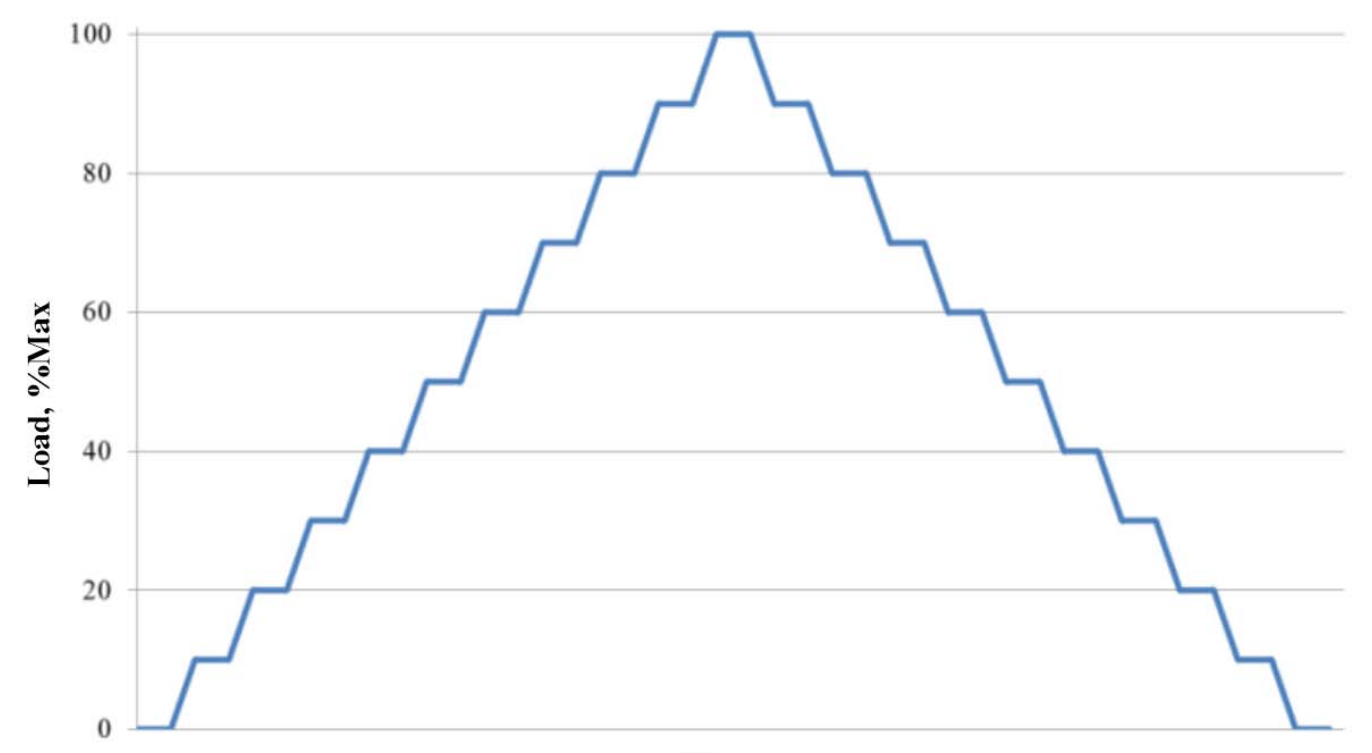

Time, $\mathrm{s}$

Figure 9. Shot bag load profile. 


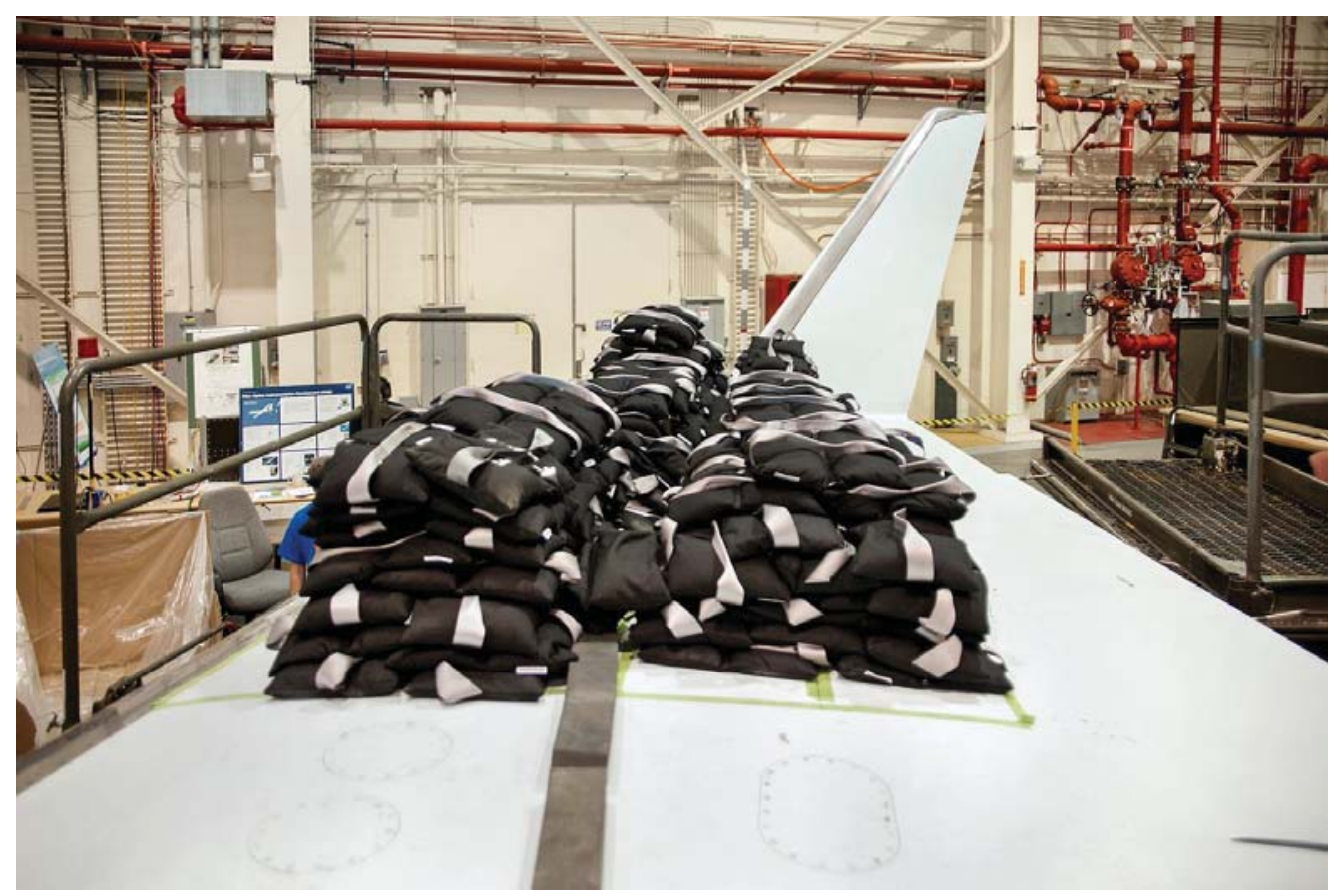

Figure 10. Photo of shot bags in place for maximum down load.

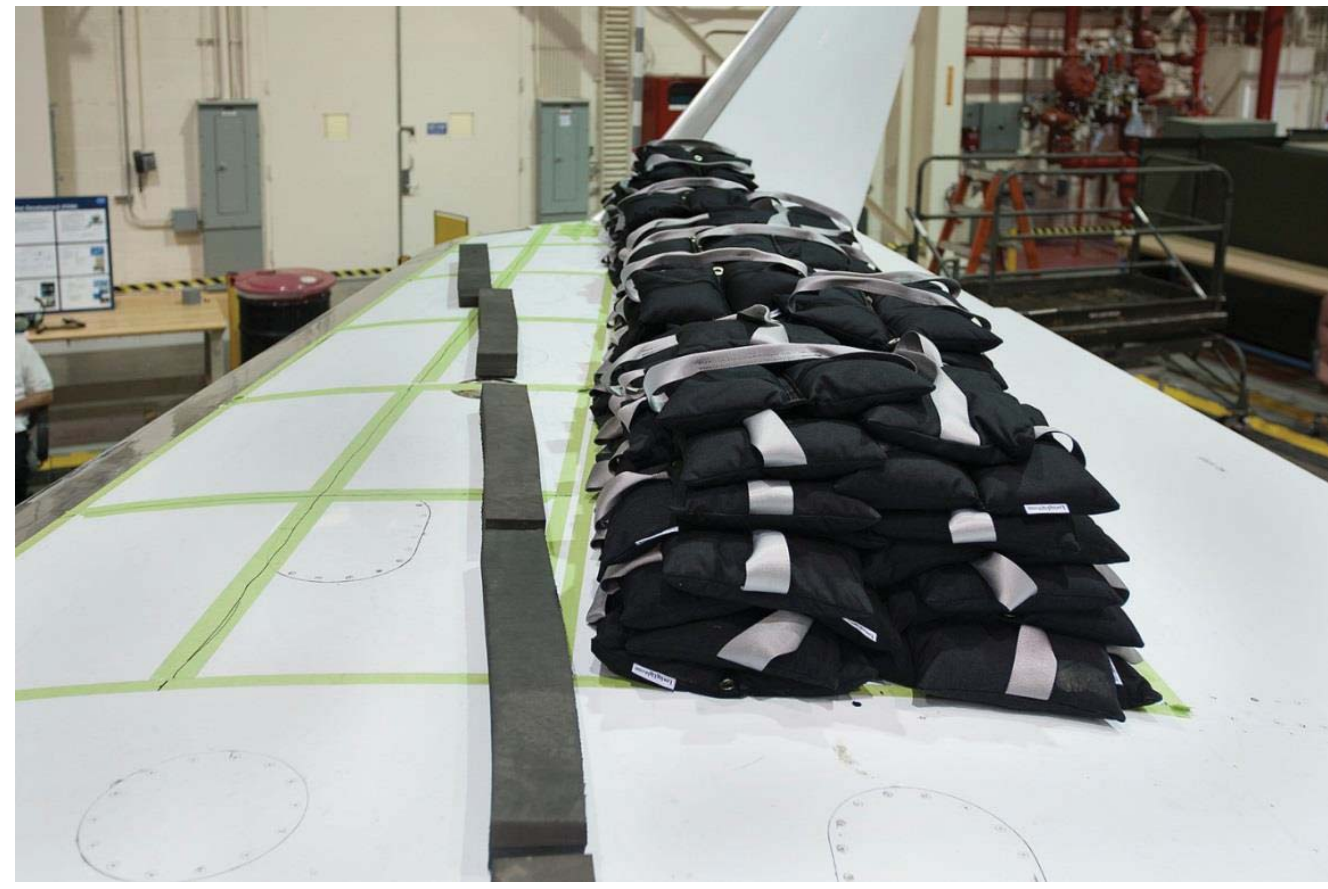

Figure 11. Photo showing 2-inch thick foam vortex generator protectors and shot bags on aft load zones. 


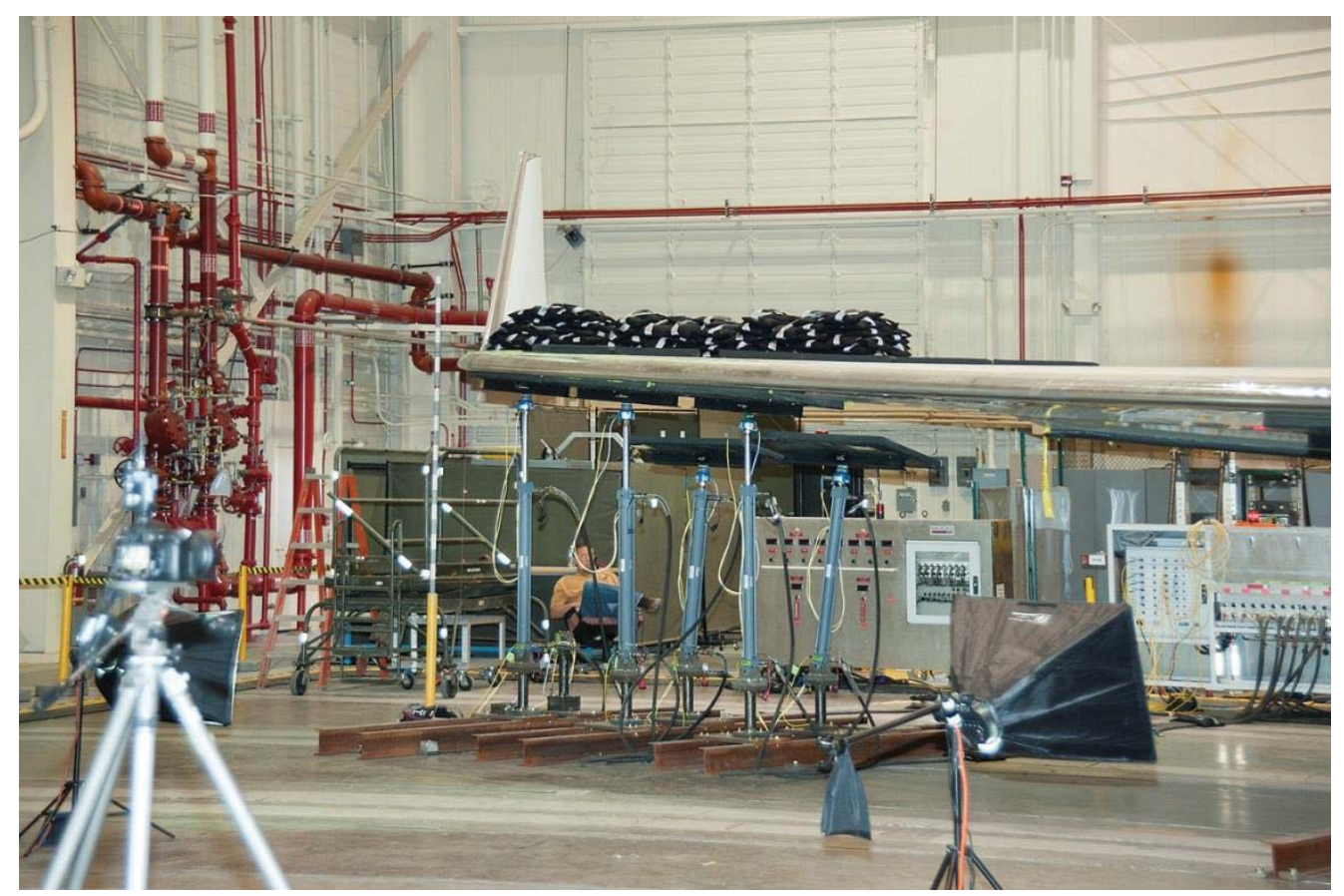

Figure 12. Photo of max torque case using hydraulic loads on front zones and shot bags on aft zones (load case 3).

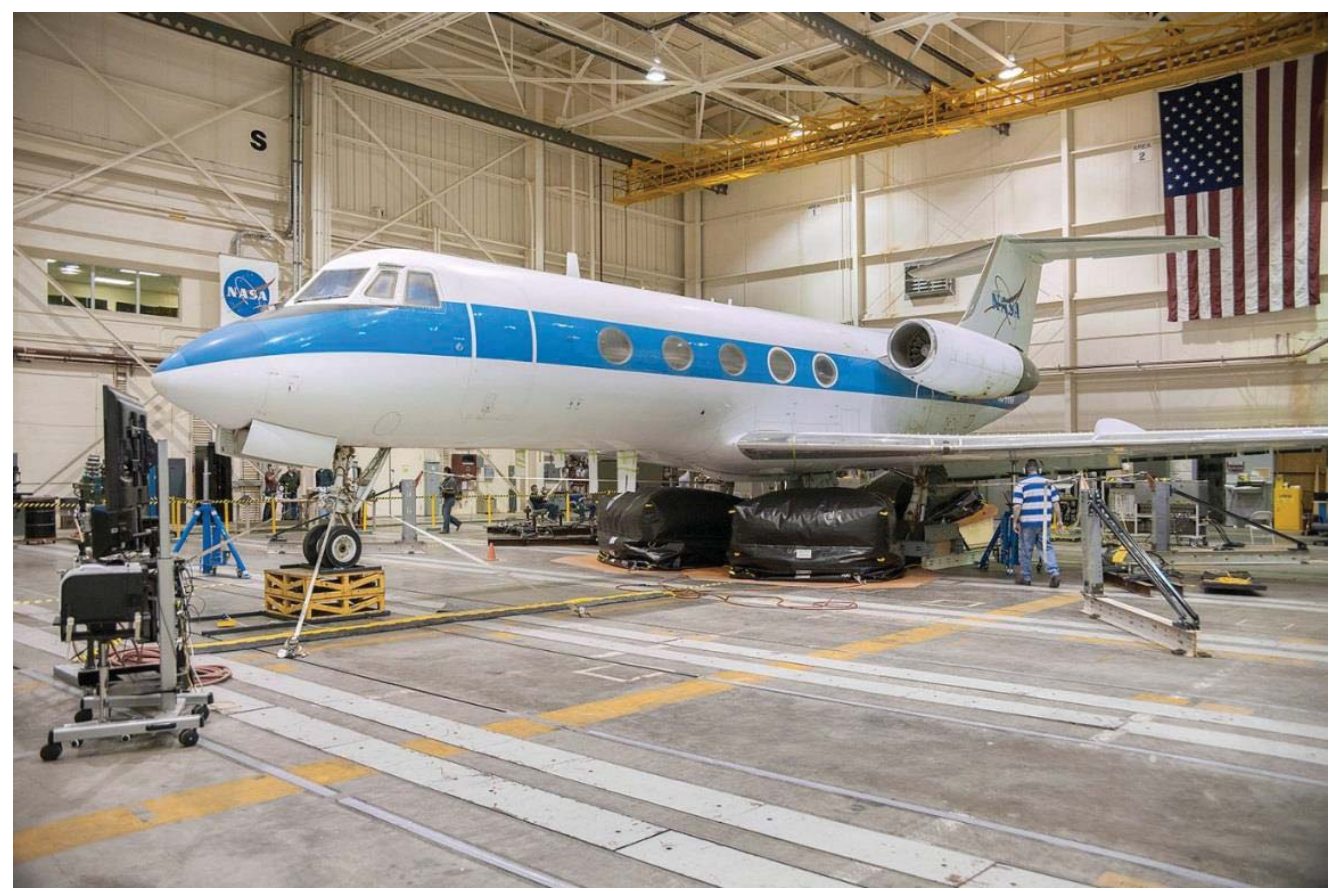

Figure 13. Photo of surrogate aircraft being prepared for practice airbag lift. 


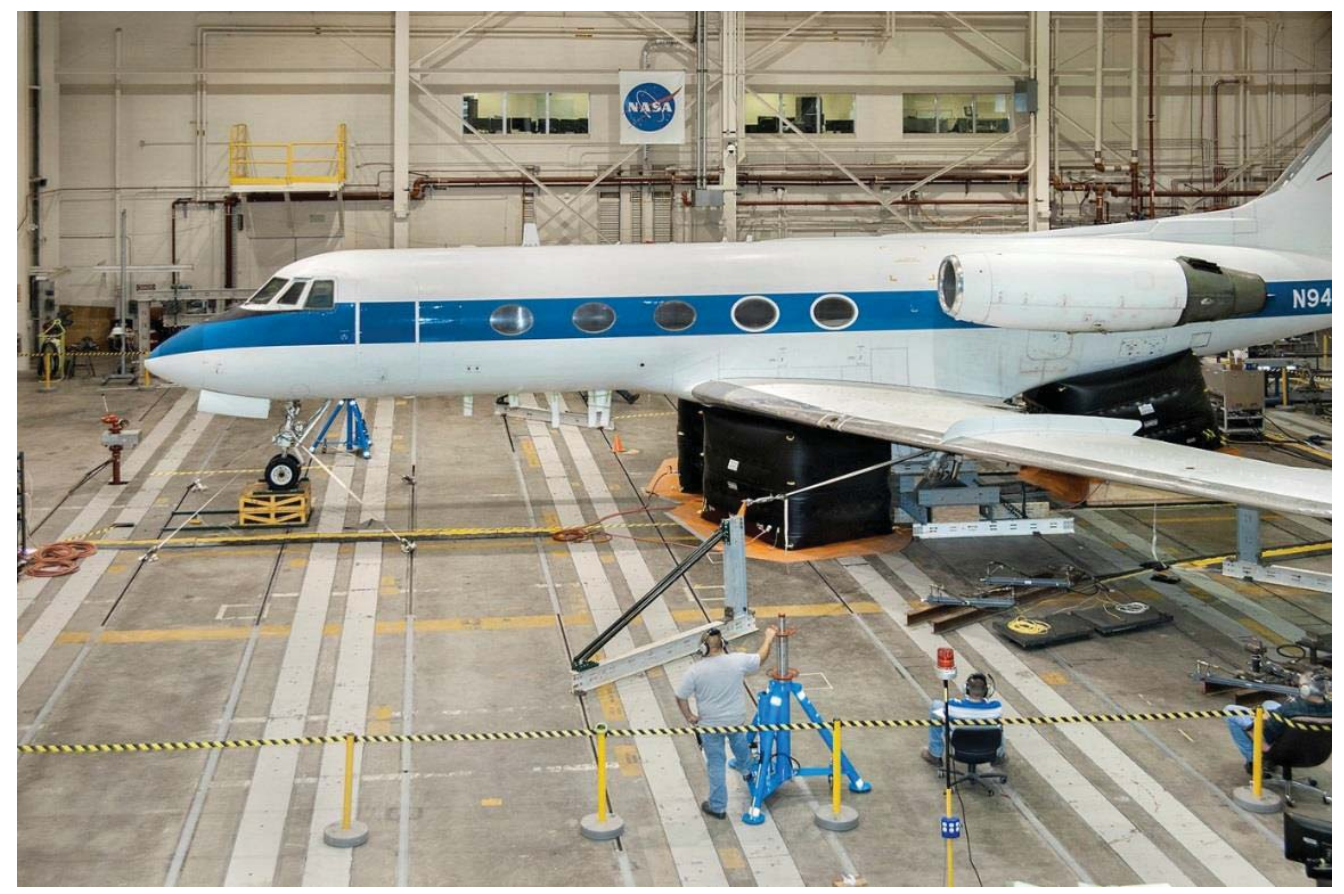

Figure 14. Photo of practice airbag lift.

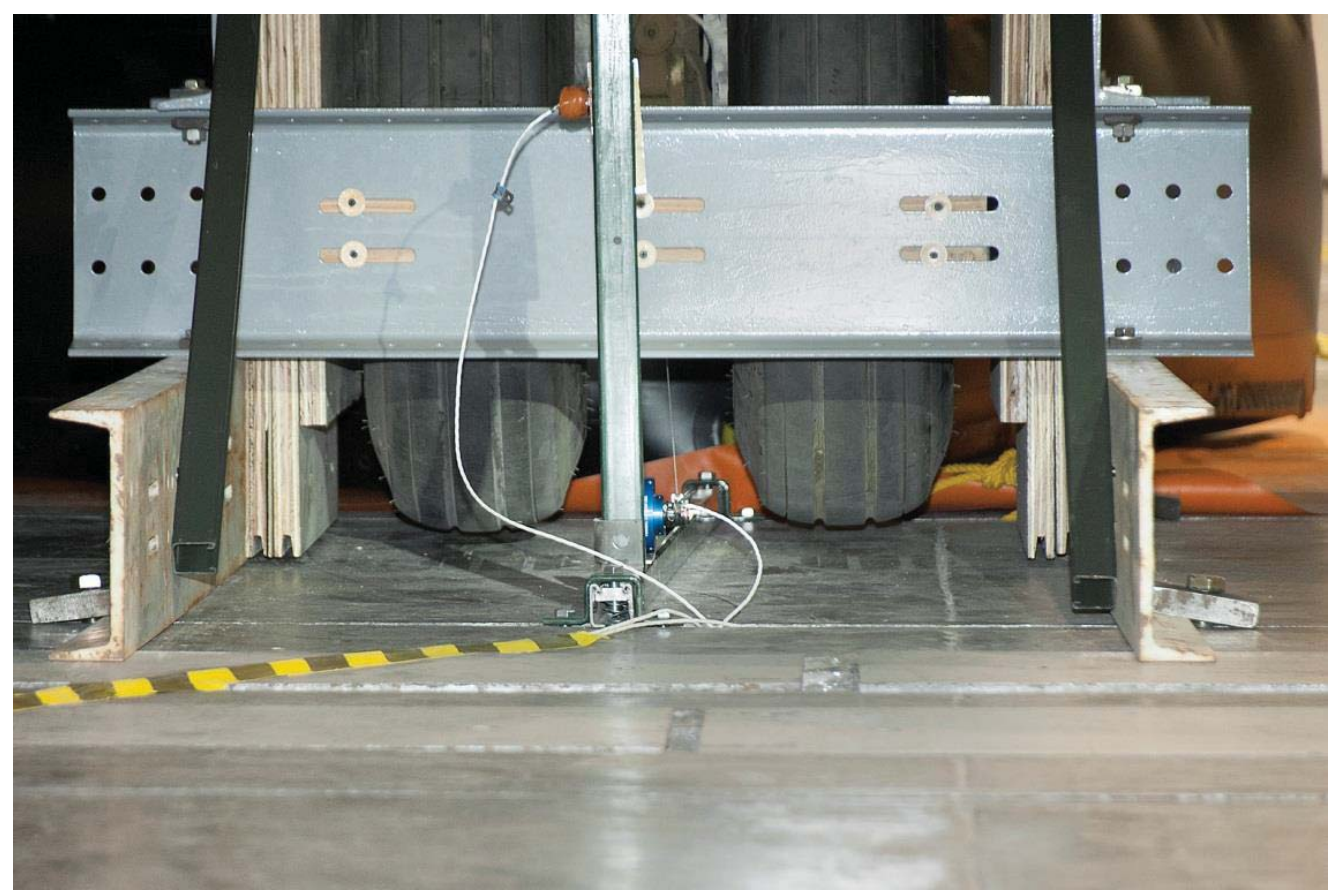

Figure 15. Photo of main gear in wheel box showing desired air gap under tires and string pot. 


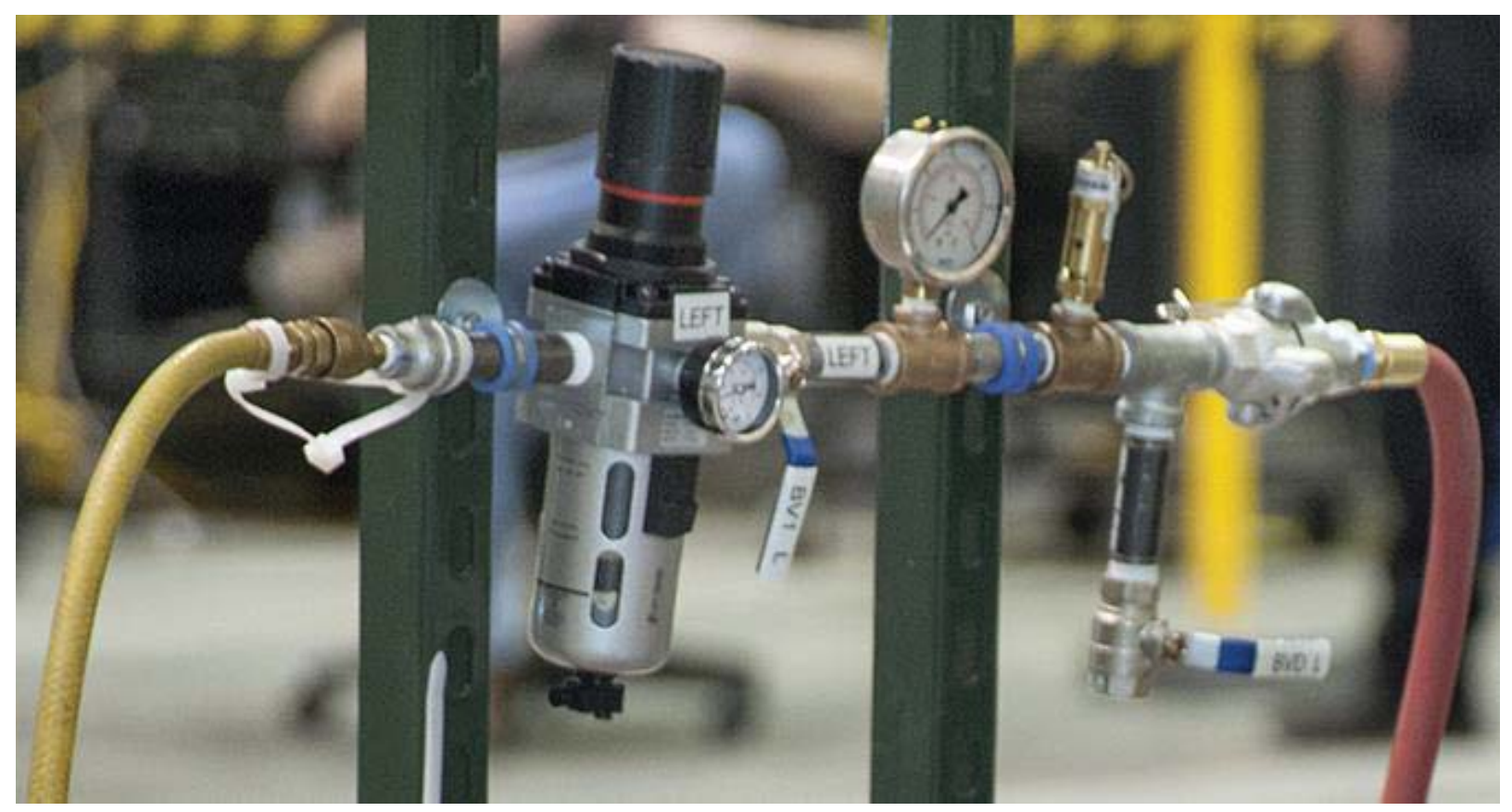

Figure 16. Photo of left airbag manifold showing (from left to right) supply air, supply regulator, supply ball valve, pressure gage, pressure relief valve, dump valve, and feed line to airbag.

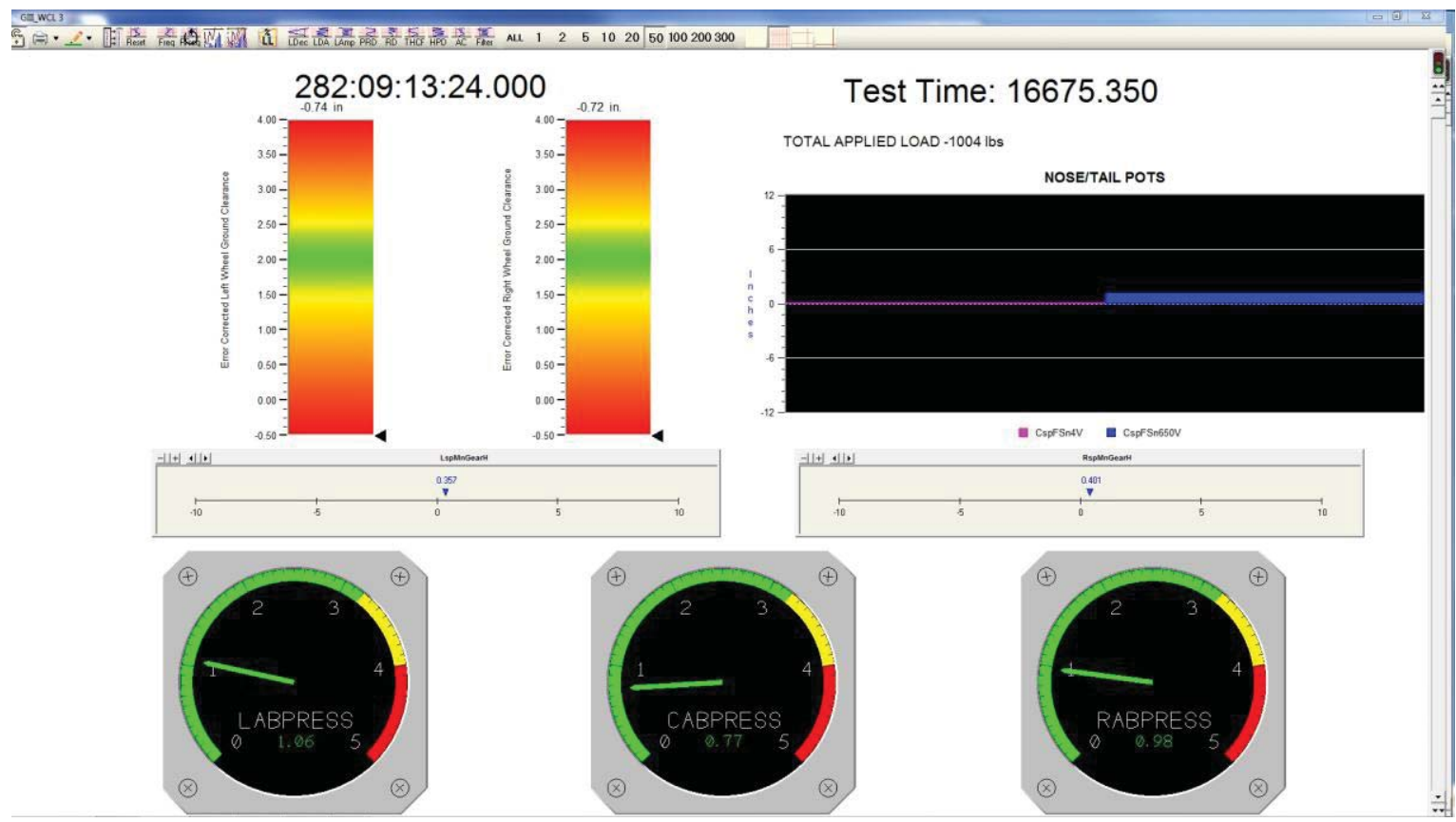

Figure 17. Photo of data acquisition display for airbag operation. 


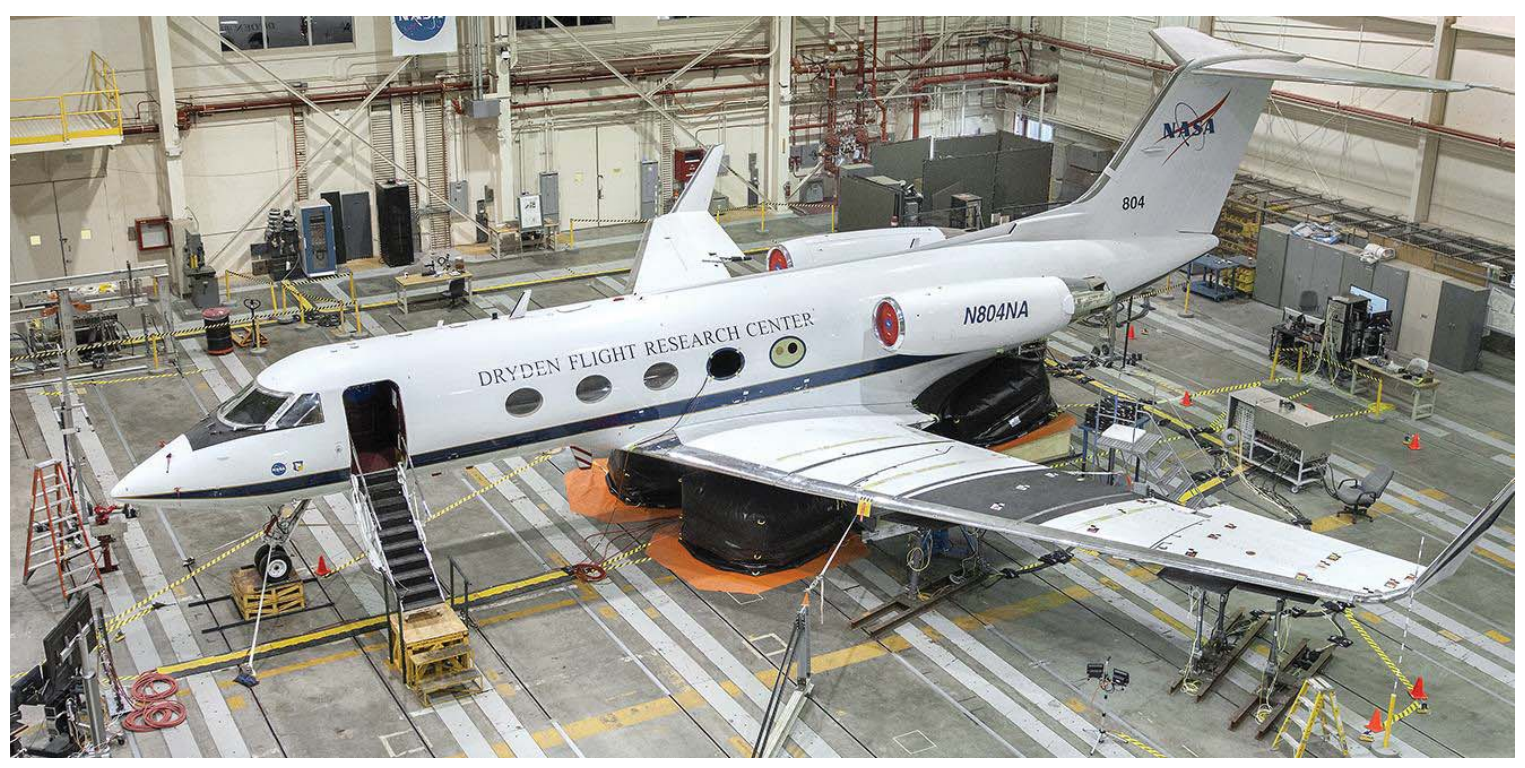

Figure 18. Photo of GIII aircraft configured for check load testing.

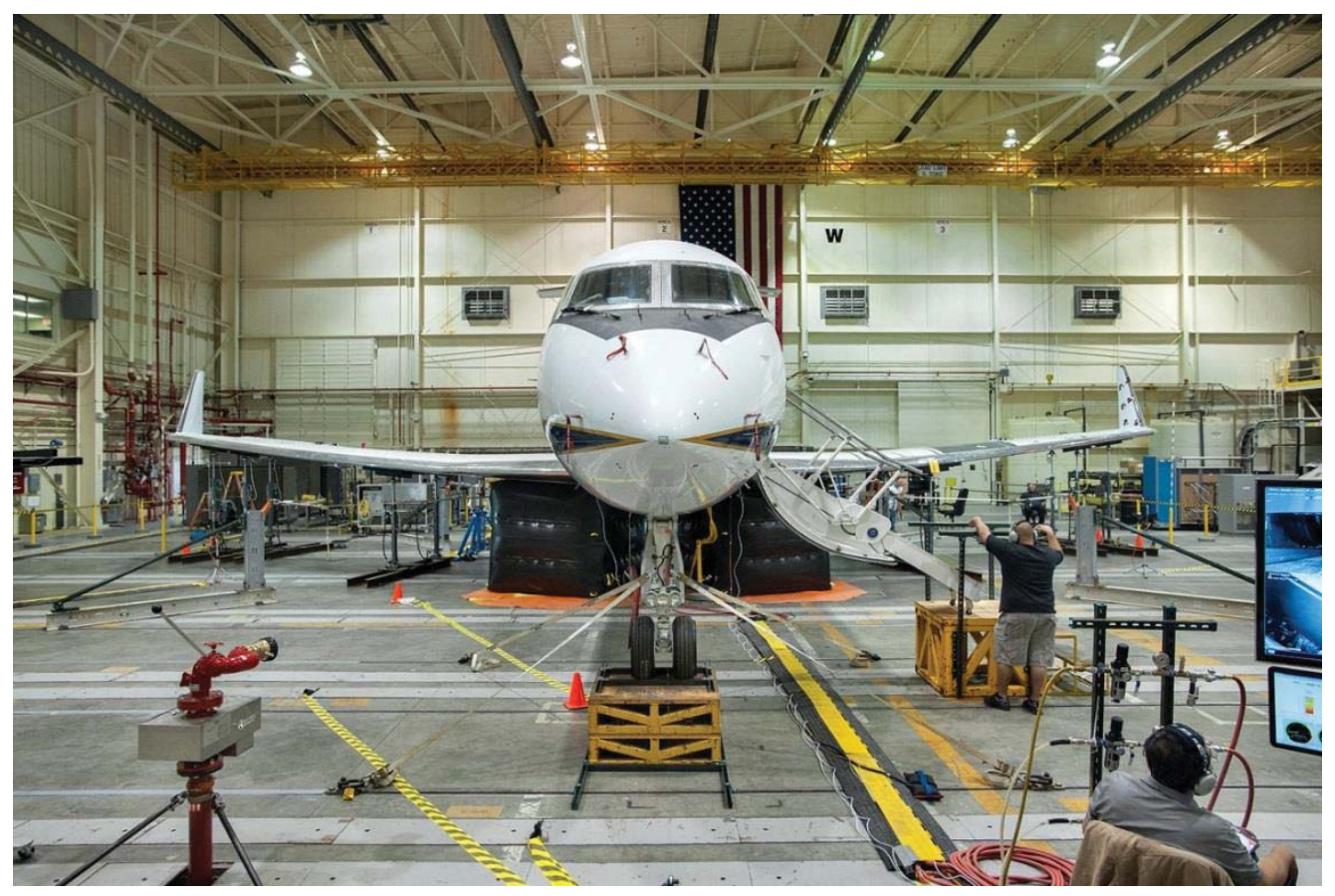

Figure 19. Photo of max up load during aileron binding check (note open cabin door). 


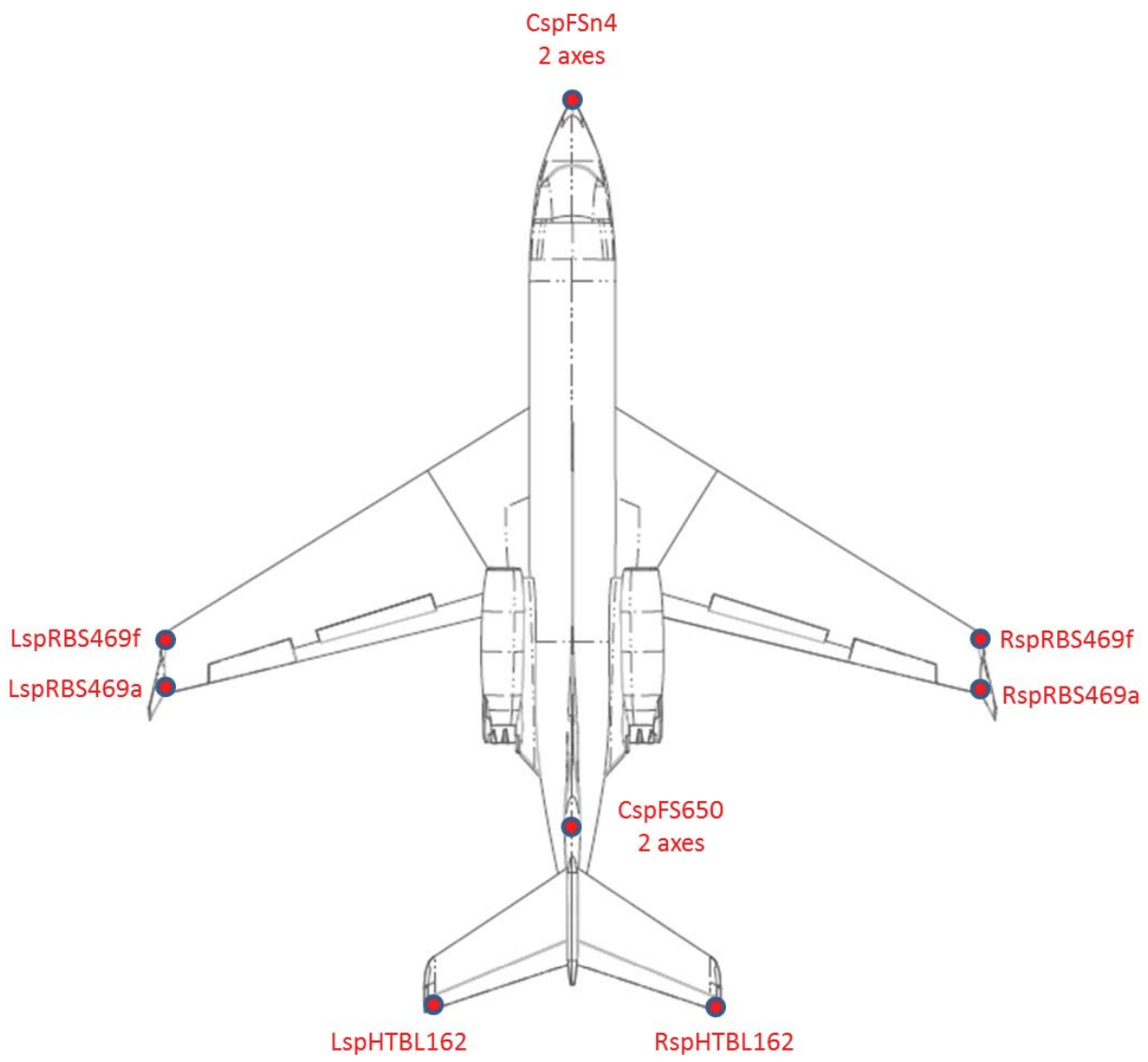

Figure 20. String potentiometer locations.

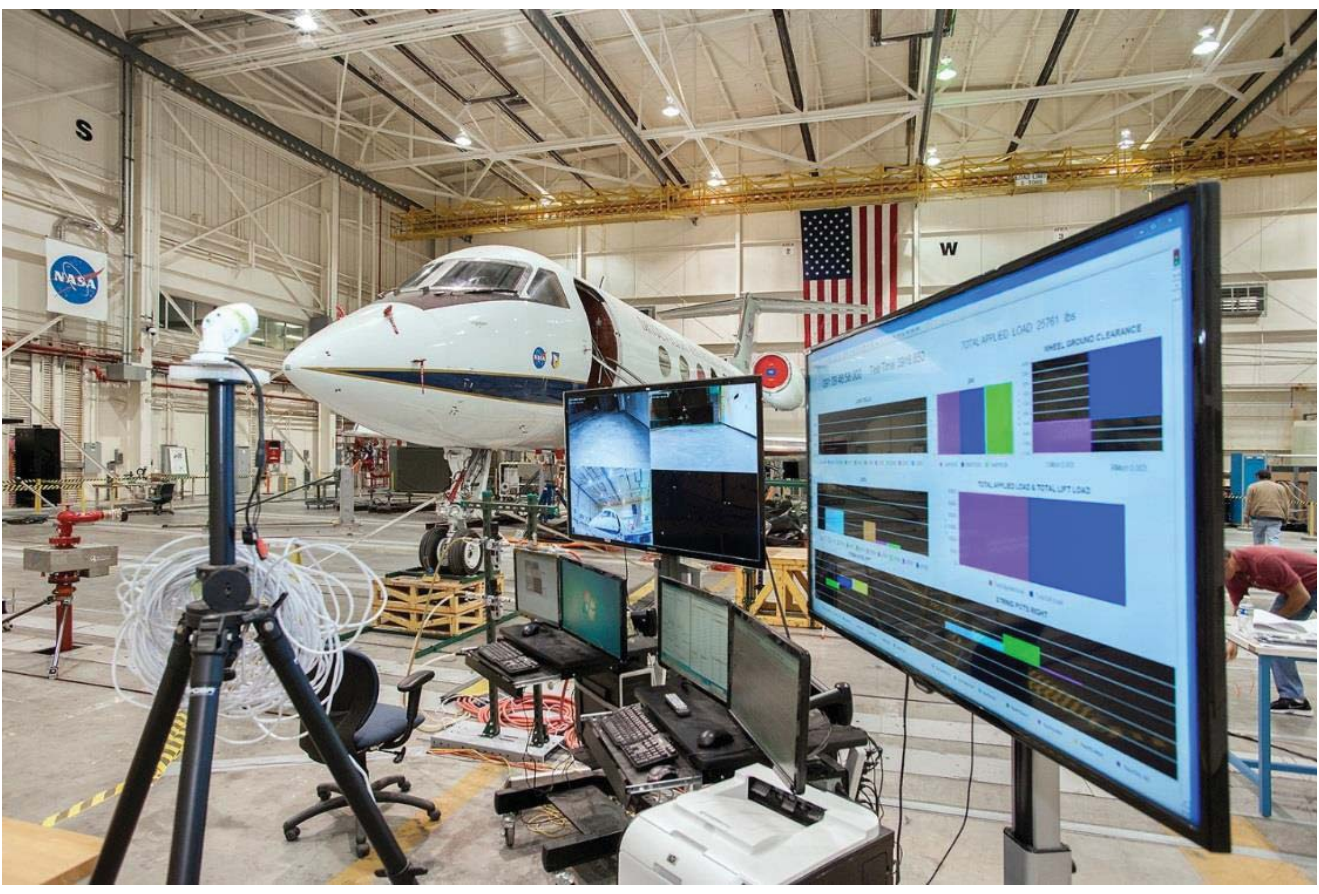

Figure 21. Photo of test information displays near aircraft nose. 

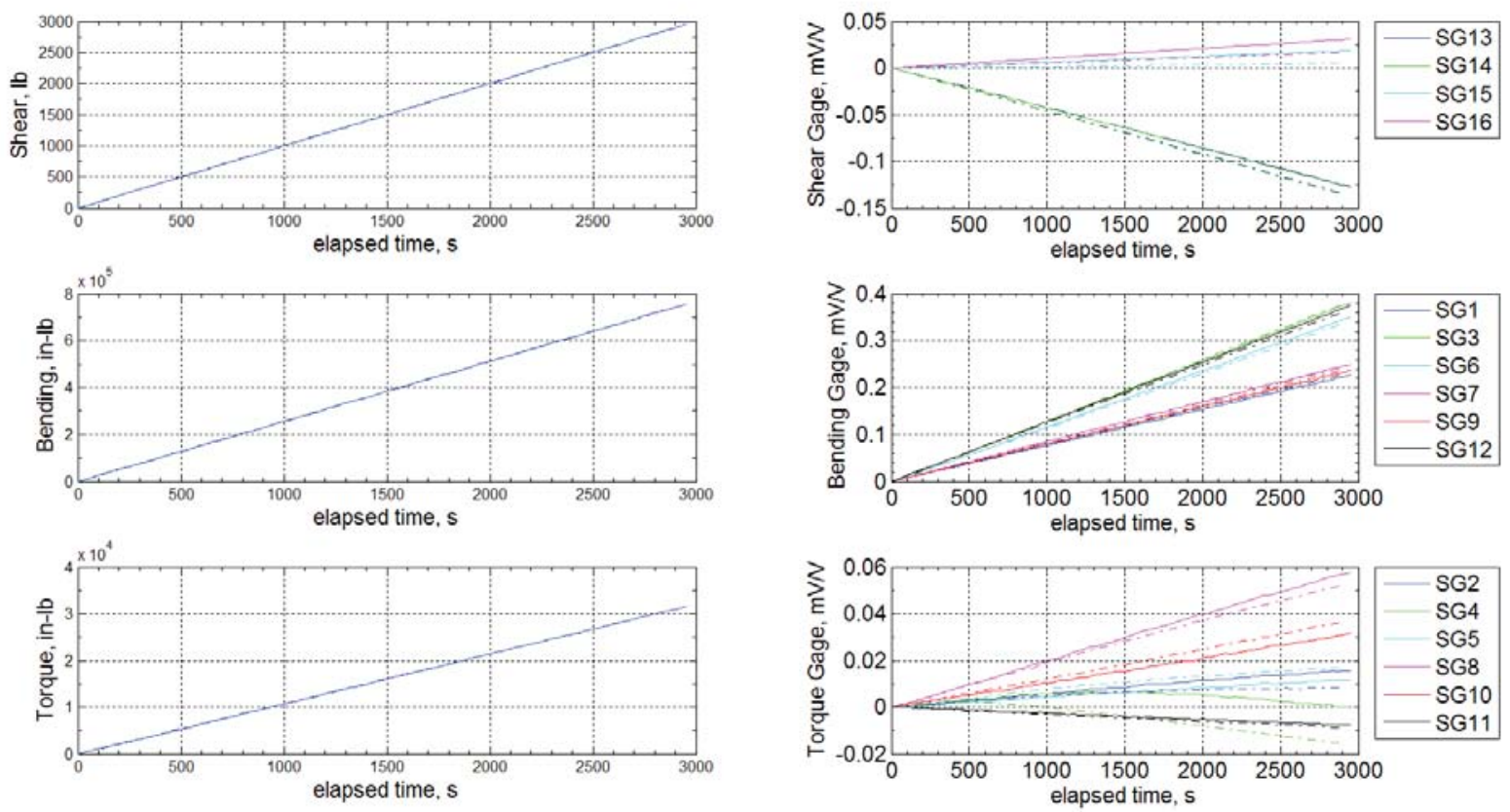

Solid Line - Load Calibration Test Dashed Line - Check Load Test

Figure 22. Plots of applied loads and strain gage time histories at RBS 152. 